Article

\title{
Experimental and Analytical Investigations of the Use of Groove-Epoxy Anchorage System for Shear Strengthening of RC Beams Using CFRP Laminates
}

\author{
Khalid Mohamed ${ }^{1}{ }^{(}$, Jamal A. Abdalla ${ }^{2, *}$ and Rami A. Hawileh ${ }^{2}$ \\ 1 Formerly Graduate Student, American University of Sharjah; Sharjah P. O. Box 26666, UAE; \\ b00066746@alumni.aus.edu \\ 2 Civil Engineering, American University of Sharjah, Sharjah P. O. Box 26666, UAE; rhaweeleh@aus.edu \\ * Correspondence: jabdalla@aus.edu
}

Received: 13 July 2020; Accepted: 27 September 2020; Published: 30 September 2020

check for updates

\begin{abstract}
Reinforced concrete $(\mathrm{RC})$ beams strengthened in shear with carbon fiber reinforced polymer (CFRP) laminates as externally bonded reinforcement (EBR) usually fail due to debonding. This paper presents an experimental and analytical investigation on the use of groove-epoxy as an anchorage system for CFRP plates and sheets bonded on both sides of shear deficient RC beams. The aim of this study is to assess the effectiveness of using groove-epoxy in enhancing the shear capacity of RC beams. Nine rectangular RC beams were strengthened with CFRP plates and sheets with groove-epoxy anchorage systems of different groove widths and tested under four point bending. It is observed that the RC beams strengthened with the groove-epoxy anchorage system showed an increase in the shear-strength over the unstrengthened control beam up to 112 and $141 \%$ for plates and sheets, respectively. Also, the increase of shear-strength contribution of the groove-epoxy system to that of CFRP without grooves ranged between 30-190\% for CFRP plates and between 40-100\% for CFRP sheets. Generally, the contributions of groove-epoxy on shear-strength decreased with the increase of groove width. Moreover, shear strength prediction models, based on modifications of the ACI440.2R-17 shear model, were developed by incorporating groove factors as a modifier to the FRP shear-strength contribution. The developed models predicted the experimental shear-strength of the tested RC beams with a good level of accuracy, with an average mean absolute percent error $(\mathrm{MAPE})=3.31 \%$ and $6.68 \%$, normalized mean square error $(\mathrm{NMSE})=0.072,0.523$, and coefficient of determination $\mathrm{R}^{2}=0.964,0.691$, for plates and sheets, respectively.
\end{abstract}

Keywords: carbon fiber reinforced polymer (CFRP); externally bonded reinforcement (EBR); groove-epoxy; shear strengthening; RC beams; anchorage systems; EBR on grooves (EBROG)

\section{Introduction and Background}

Reinforced concrete (RC) beams strengthened in shear with carbon fiber reinforced polymer (CFRP) laminates as externally bonded reinforcement (EBR) usually fail due to premature debonding. This usually takes place well before the CFRP utilizes its full tensile strength. To delay or prevent premature deboning, several anchorage techniques have been suggested and employed. The rehabilitation of deteriorated old structures such as buildings, bridges, parking structures, marine structures has become a major issue during the last four decades. This issue has been addressed by many researchers to develop methods and techniques to strengthen, repair, and retrofit such structures.

Strengthening of the deteriorated structures, using externally bonded reinforcement (EBR) materials became one of the most widely used strengthening methods as given by several comprehensive reviews and surveys [1-6]. During the last three decades, carbon fiber reinforced polymer (CFRP) 
composites have become the material of choice that has been used widely for flexure and shear strengthening in the construction industry. This is because it has many advantages, especially in its physical and chemical properties, such as high tensile strength, light weight, and high resistance to corrosion [7-14].

Prior to CFRP materials, other materials have been used in shear and flexural strengthening applications such as steel [15-20]. Recently aluminum alloys have been used as externally bonded reinforcement material for both shear and flexure [21-29]. Beams are one of major elements in buildings, bridges, and other structures and they can fail in flexure or shear. When strengthening RC beams against shear with CFRP, the fibers do not reach their ultimate strength and mostly debonding of the CFRP happens prematurely. To increase the utilization of the CFRP strength, end anchorage become necessary, especially when the length of the CFRP is limited and the bonded length after a critical section is not enough to reach the ultimate strength of the CFRP laminates. In addition, the problem of premature peeling is also a concern, especially when strengthening a T-section beam because the shear strengthening is only located on the web of the member and the CFRP laminates may end below the position of the neutral axis. As shear strengthening, CFRP has been used extensively as an EBR without anchorage which resulted in premature debonding. Accordingly, many anchorage systems have been developed and used in order to solve the problem of debonding of CFRP sheets or plates by anchoring them to the stem of the beam [30-39]. Mohee et al. [31] and Kalfat et al. [32] presented a detailed review of use of anchors in general in externally bonded reinforcement using FRP. Mhanna, et al. [35] provided experimental results of shear strengthening of reinforced concrete beams using CFRP wraps. Their experimental test results showed that the beam strengthened by U-Wrapped CFRP sheets increased the shear strength of the tested beams significantly. Mohammed et al. [36] carried an experimental investigation for on using bore-epoxy anchorage system to delay debonding of CFRP plates strengthened concrete beams. They concluded that the use of bore-epoxy delays the debonding of CFRP plates and therefore increased the shear capacity of the tested beams. Koutas et al. [37], Kim et al. [38], and Chen et al. [39] used anchors including CFRP U-strips in shear strengthening of reinforced concrete T-beams with FRP. All reported significant increase in shear capacity due to use of anchors. Furthermore, contributions of externally bonded flexural CFRP laminates in the shear strengthening of RC beams have been investigated by several researchers [40-43]. Shear strengthening of RC beams is usually achieved by externally bonding CFRP sheets or plates to the vertical sides of the beam's web with different orientation and spacing using epoxy adhesives. In some situations, the sides of the beam might not be accessible for shear strengthening or might be too shallow to develop the strength of the CFRP laminates without anchors. As a result, flexural reinforcement using CFRP sheets or plates, which are attached to the beam's soffit, has been used to increase the shear capacity of RC beams. Hawileh et al. $[40,41]$ carried out an experimental study to assess the contributions of flexural CFRP sheets on the shear capacity of RC beams, while Nawaz et al. [42] and Saqan et al. [43] conducted experimental investigation to evaluate the contributions of flexural CFRP plates on the shear capacity of RC beams. They concluded that the shear capacity of RC beams strengthened with CFRP sheets as flexural reinforcement increased by about $10-70 \%$ over the control unstrengthened specimen and by about $13-138 \%$ for those strengthened with CFRP plates as flexural reinforcement. These studies validated the significant contributions of flexural CFRP sheets and CFRP plates on enhancing the shear capacity of strengthened RC beams.

This study focused on the use of anchorage system in shear strengthening of shear deficient beams using CFRPs plates and sheets as externally bonded reinforcements. Different variables of the anchorage system used have been investigated. The anchorage system investigated in this study is called externally bonded reinforcement on grooves (EBROG) [44-46]. The significance of this research is to explore the effect of this type of anchorage system in increasing the shear capacity of RC beams.

Grooving method (GM) includes digging grooves into tension face of concrete beams and filling them with epoxy resin then bonding the CFRP sheets or plates on top of the filled grooves for flexure reinforcement. Mostofinejad et al. [45] applied the EBROG on a set of small-scale beams, 
where some were strengthened against shear with FRP strips with EBR only and some with EBR on groove (EBROG) method. They found that the beams strengthened with EBR method only showed an increase in the load capacity of 10-13\% over the unstrengthened control beam and they failed by FRP debonding, while beams strengthened with EBROG method showed an increase in the load capacity of $17-23 \%$ over the unstrengthened control beam and they failed in flexure. A follow up study has been carried out by Mostofinejad et al. [46] using EBROG method for shear strengthening of small RC rectangular beams using CFRP sheets. They concluded that strengthening with CFRP sheets using the EBROG method resulted in a $23 \%$ increase in the flexural strength of the beams over the control beam. Moreover, premature debonding has been eliminated and the failure mode has changed from shear to flexural failure with a ductile behavior. Aiming for a comparison investigation for the bond strength between FRP and concrete with externally bonded reinforcement (EBR) and externally bonded reinforcement on grooves EBROG techniques, Hosseini et al. [44] carried out a single shear bond test on prism specimens. They concluded that the EBROG method on prisms has increased the load capacity by $55.5 \%$ when compared with conventional EBR method. Other studies were carried out to assess the bond strength of CFRP sheets and strips using EBROG [47-50]. Mostofinejad et al. [51,52] used another method called externally bonded reinforcement in grooves (EBRIG) for strengthening concrete beams against shear where the difference is that here the grooves are in direct contact with the fibers by inserting the fibers into the grooves. The authors compared EBRIG with the conventional EBR method where they used two-sided, U-shape, and fully wrapped FRP strips for strengthening. They concluded that the EBRIG method combined with the full wrapping has the best performance among all the other with an increase in load capacity by $148 \%$ over the control beam, in addition, they noticed that the EBRIG method has changed the failure mode from a brittle shear failure to flexural failure.

Contrary to the previous investigations, this study proposes applying externally bonded reinforcement on grooves on large scale rectangular concrete beams deficient in shear and the mechanism will referred to as groove-epoxy anchorage system. Therefore, the objectives of this study are to: (1) investigate experimentally the effect of using two sided CFRPs sheets and plates on shear strengthening of shear deficient RC beams; (2) examine the effect of using groove-epoxy anchorage systems on the bond between the CFRP laminates and concrete surfaces, tensile strain on CFRP laminates, and beam shear capacity; (3) study the different modes of failure of the strengthened beams when subjected to four points bending; (4) develop analytical models to predict the shear strength of the tested specimens strengthened with CFRP using groove-epoxy anchorage system; (5) use ACI 440.2R-17 provisions to calculate the shear strength of the strengthened RC beams and compare them with the experimental results and with the values predicted by the developed models. The statistical measures such as mean absolute percent error (MAPE), normalized mean square error (NMSE), and coefficient of determination (R2) were used to measure the accuracy of predictions for the developed models compared to experimental values.

\section{Materials and Methods}

A total of nine rectangular RC beams were prepared and tested under four points bending, and they are designed and reinforced in such a way that they have sufficient flexural capacity and fail in shear.

\subsection{Specimen Details and Test Matrix}

\subsubsection{Specimen Details}

Figure 1 shows the longitudinal section of the beam with reinforcement details. Stirrups, as shear reinforcement, were provided on one side of the beam while the other side was not reinforced with stirrups and therefore it is shear deficient. As shown in Figure 1, the beam specimen dimensions are $1840 \times 200 \times 300 \mathrm{~mm}$. Figure 1 also shows the cross section of the beam with reinforcement details. As shown, the beams were reinforced in flexure with $4 \varnothing 16 \mathrm{~mm}$ bars in the tension zone located at 
$259 \mathrm{~mm}$ from the top of the beam. In the compression zone, the beam specimen is reinforced with $2 \varnothing 12 \mathrm{~mm}$ bars. Each beam was internally reinforced against shear using stirrups of $\varnothing 8$ at $50 \mathrm{~mm}$ center to center as shown in Figure 1.

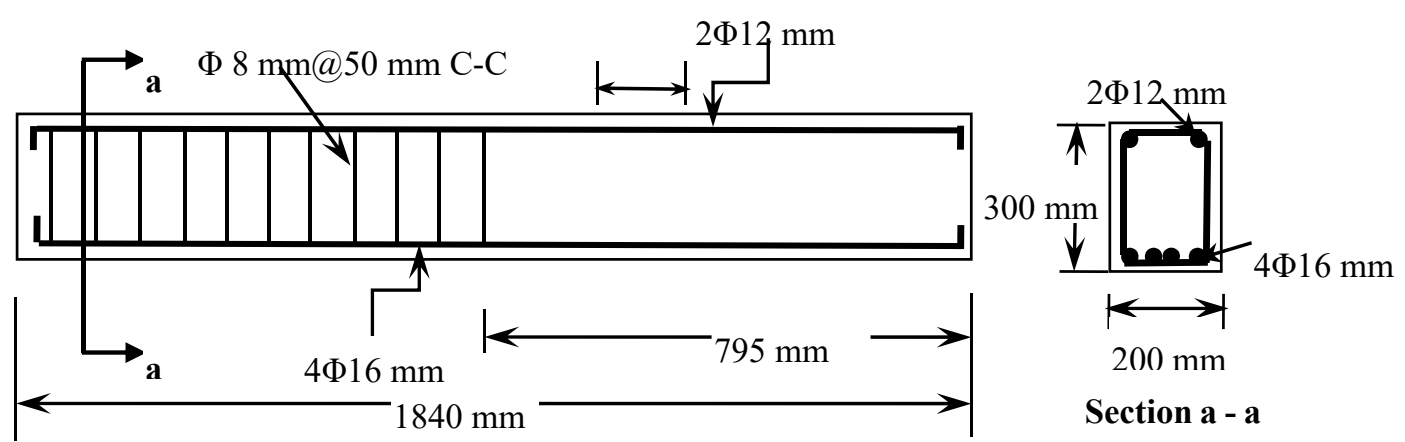

Figure 1. Longitudinal and cross-section details of the beam specimen.

\subsubsection{Specimens Designation and Test Matrix}

As indicated, the nine beams were designed and cast in such a way that the shear failure controls when tested under four points bending. The beams were strengthened using CFRP sheets and plates with two-sided wrapping. Two beams were strengthened using EBR method with CFRP sheets and plates and were designated as S-EBR and P-EBR, respectively. Three beams were strengthened with CFRP sheets using groove-epoxy system with thin, medium, and dense grooves (Figure 2a) and were designated as SGT, SGM, and SGD, respectively where SGT indicates CRFP sheet on thin groove, SGM indicates CFRP sheet on medium groove, and SGD indicates CFRP sheet on dense groove. Similarly, three other beams were strengthened with CFRP plates using groove-epoxy system with thin, medium, and dense grooves and were designated as PGT, PGM, and PGD, respectively where SGT indicates CRFP plate on thin groove, SGM indicates CFRP plate on medium groove and SGD indicates CFRP plate on dense groove. Figure $2 b$ shows a sample beam strengthened with thin groove-epoxy system, two grooves of $10 \mathrm{~mm}$ in depth and $5 \mathrm{~mm}$ in width were engraved and these two grooves were placed under each of CFRP laminate. Similar procedures were followed for medium $(10 \mathrm{~mm})$ and dense $(40 \mathrm{~mm})$ grooves.

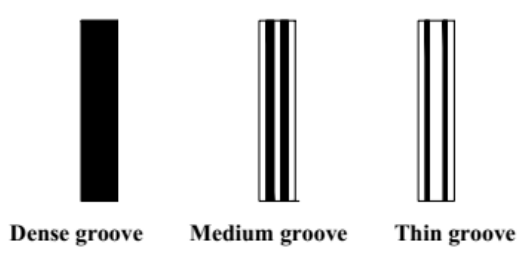

(a)

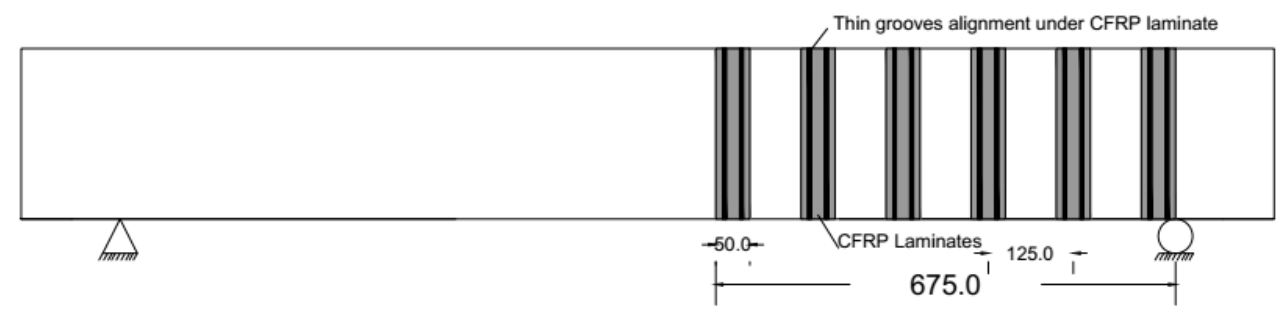

(b)

Figure 2. CFRP laminates and grooves alignment (all dimensions are in $\mathrm{mm}$ ); (a) all groove types; (b) grooves on beam stem. 
Table 1 shows the details of the test matrix. It includes a control beam which is unstrengthened and eight strengthened beams. Two of them with EBR and the remaining six with thin $(5 \mathrm{~mm})$, medium $(10 \mathrm{~mm})$ and dense $(40 \mathrm{~mm})$ groove-epoxy anchorage system using plates and sheets of $50 \mathrm{~mm}$ in width. The CFRP sheets and plates were spaced at $125 \mathrm{~mm}$ with two-sided wrapping as shown in Figure $2 b$.

Table 1. Details of the test matrix.

\begin{tabular}{|c|c|c|c|c|c|c|}
\hline No & Specimen & FRP Type & $\begin{array}{l}\text { Strengthening } \\
\text { Technique }\end{array}$ & $\begin{array}{l}\text { Groove Width } \\
\text { (mm) }\end{array}$ & $\begin{array}{l}\text { FRP Width } \\
\text { (mm) }\end{array}$ & $\begin{array}{c}\text { FRP Spacing } \\
\mathrm{S}_{\mathrm{f}}(\mathrm{mm})\end{array}$ \\
\hline 1 & $\mathrm{C} 1$ & - & $\begin{array}{l}\text { Control Beam } \\
\text { Unstrengthen }\end{array}$ & - & - & - \\
\hline 2 & S-EBR & Sheet & $\begin{array}{l}\text { EBR } \\
\text { Thin }\end{array}$ & - & 50 & 125.0 \\
\hline 3 & SGT & Sheet & $\begin{array}{c}\text { Groove-Epoxy } \\
\text { Anchor } \\
\text { Medium }\end{array}$ & 5 & 50 & 125.0 \\
\hline 4 & SGM & Sheet & $\begin{array}{c}\text { Groove-Epoxy } \\
\text { Anchor } \\
\text { Dense }\end{array}$ & 10 & 50 & 125.0 \\
\hline 5 & SGD & Sheet & $\begin{array}{c}\text { Groove-Epoxy } \\
\text { Anchor }\end{array}$ & 40 & 50 & 125.0 \\
\hline 6 & P-EBR & Plate & $\begin{array}{l}\text { EBR } \\
\text { Thin }\end{array}$ & - & 50 & 125.0 \\
\hline 7 & PGT & Plate & $\begin{array}{c}\text { Groove-Epoxy } \\
\text { Anchor } \\
\text { Medium }\end{array}$ & 5 & 50 & 125.0 \\
\hline 8 & PGM & Plate & $\begin{array}{c}\text { Groove-Epoxy } \\
\text { Anchor } \\
\text { Dense }\end{array}$ & 10 & 50 & 125.0 \\
\hline 9 & PGD & Plate & $\begin{array}{c}\text { Groove-Epoxy } \\
\text { Anchor }\end{array}$ & 40 & 50 & 125.0 \\
\hline
\end{tabular}

\subsection{Material Properties}

\subsubsection{Concrete}

All beams were cast using normal weight concrete mixes of comparable compressive strengths. Three cubes and three cylinders were prepared for each beam and were tested after 28 days. Figure 3a shows mode of failure of for cubes and Figure $3 b$ show mode of failure for cylinders. Several cubes and cylinders were tested and their average cube strength of $\mathrm{f}_{\mathrm{cu}}=54.4 \mathrm{MPa}$ and average cylinder strength of $\mathrm{f}_{\mathrm{c}}=41.0 \mathrm{MPa}$. No study of the microstructural changes was performed since only the final compressive strength of concrete was the main objective.

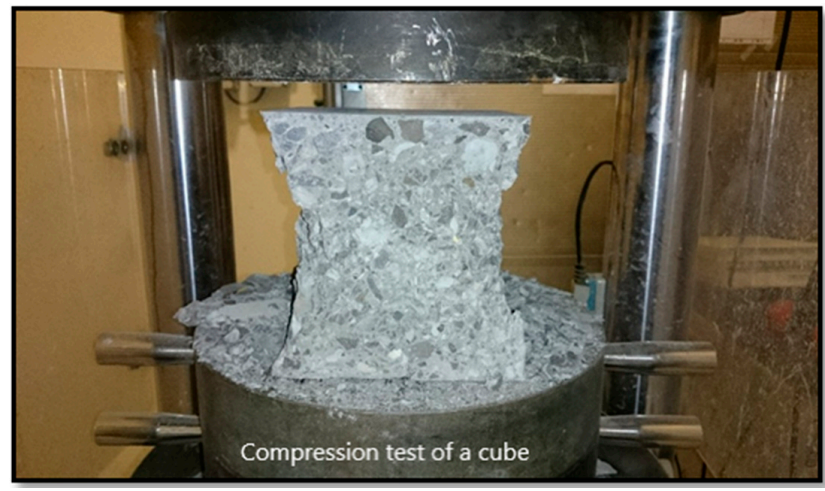

(a)

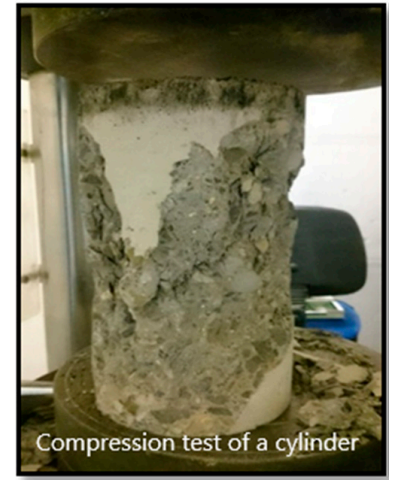

(b)

Figure 3. Failure modes of concrete cube and concrete cylinders failure: (a) Concrete cube failure mode; (b) Concrete cylinder failure mode. 


\subsubsection{Steel}

Three specimens of steel bars, conforming to ASTM 615, have been tested at a loading rate of $10 \mathrm{~mm} / \mathrm{min}$ using a universal testing machine (UTM). Three steel bar specimens were tested, and their average yield strength and modulus of elasticity were 590.4 MPa and 199.9 MP, respectively.

\subsubsection{CFRP and Epoxy}

Sheets are flexible woven FRP filaments or fibres like fabrics and they can be unidirectional or bidirectional. The sheets used in this investigation are unidirectional. Plates are solid laminate of FRP that are made from FRP filaments under temperature and pressure to form a solid material. Table 2 shows the mechanical properties of the CFRP sheets and plates used in this study as stated by the manufacture. CFRP sheets and plates were bonded externally to the RC beams using epoxy adhesive MapeWrap 31 and Adesilex PG2, respectively [53]. Adesilex PG2 is a two-component product based on epoxy resins, selected fine-grain aggregates, and special additives and it hardens in 5 hours' time without shrinkage. The mechanical properties of the Adesilex PG2 epoxy are also given in Table 2 [53]. MapeWrap 31 is used for the impregnation of sheets/fabrics, for strengthening RC members. MapeWrap 31 is a gelatinous, solvent-free, epoxy resin-based adhesive that is made of two pre-measured components-resin component and hardener component that must be mixed together before use [53]. Table 2 also shows the mechanical properties of MapeWrap 31.

Table 2. Mechanical properties of CFRP sheets, plates and epoxy.

\begin{tabular}{|c|c|c|c|c|c|}
\hline Material & $\begin{array}{l}\text { Thickness } \\
\text { (mm) }\end{array}$ & $\begin{array}{l}\text { Modulus of Elasticity } \\
\text { (GPa) }\end{array}$ & $\begin{array}{l}\text { Ultimate Tensile } \\
\text { Strength (MPa) }\end{array}$ & $\begin{array}{l}\text { Elongation at } \\
\text { Failure (\%) }\end{array}$ & $\begin{array}{l}\text { Density } \\
\left(\mathrm{g} / \mathrm{cm}^{3}\right)\end{array}$ \\
\hline CFRP Sheets & 0.17 & 230 & 4800 & 2.0 & 1.79 \\
\hline CFRP Plates & 1.40 & 170 & 3100 & 2.0 & 1.61 \\
\hline Adesilex PG2 & - & 6 & $\geq 18$ & - & 1.70 \\
\hline Mapewrap 31- & - & $\geq 3$ & $\geq 40$ & $\geq 1.6$ & 1.06 \\
\hline
\end{tabular}

\subsection{Specimen Preparation}

For the beams strengthened with EBR the beam surface was cleaned with a brush, place where the CFRP laminates will be attached was marked, a concrete grinder machine was used to remove the thin layer of weak concrete on the sides of the beams to make a rough surface for bonding the CFRP sheet and plates, then an air blower was used to remove all the dust. The wet layup method was then used for bonding the CFRP sheet and plates into the prepared concrete surface by applying a film of an appropriate resin (Mapewrap 31 and Adesllesx PG2) before laying the FRP. The fibers were finally saturated by applying enough resin. Excess resin was removed from the surface to prevent its adverse effect on ultimate rupture strength. For beams strengthened with groove-epoxy anchorage system, the thin, medium, and dense grooves were marked and engraved only on the beam's sides (beam stem) using the grinder (Figure $4 \mathrm{a}-\mathrm{c}$ ). The grooves were filled with epoxy adhesive and then an epoxy layer of approximately $2 \mathrm{~mm}$ was used. Finally, the CFRP sheet or plate was attached on top of the epoxy layer (beam's sides) and were impregnated with another layer of epoxy adhesive (Figure 4d). The specimens were left to cure for 7 days waiting for the epoxy to gain its full strength prior to testing.

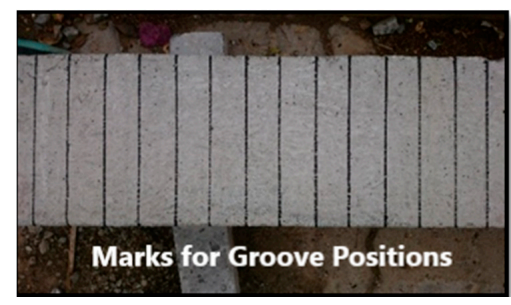

(a)

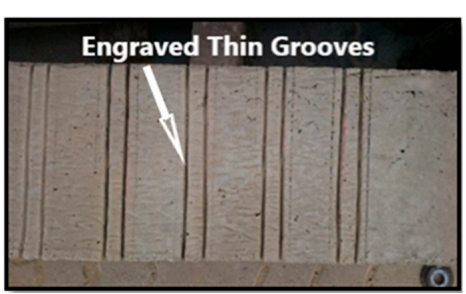

(b)

Figure 4. Cont. 


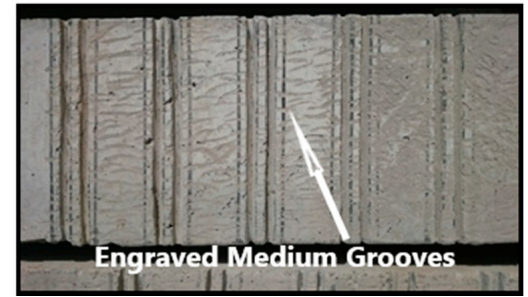

(c)

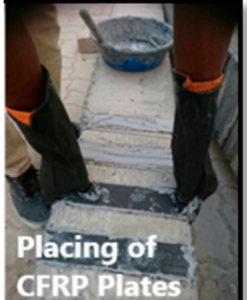

(d)

Figure 4. Specimen preparation: (a) Marking grooves position; (b) Engraving thin grooves; (c) Engraving medium grooves; (d) Placing CFRP plates and sheets.

\subsection{Test Setup and Instrumentations}

Figure 5a displays the test setup with a $250 \mathrm{~mm}$ distance between the load points. The beam clear test span was $1550 \mathrm{~mm}$ with a shear span of $650 \mathrm{~mm}$ and shear span to depth ratio (a/d) of 2.51 as shown in Figure $5 \mathrm{a}$. Figure $5 \mathrm{~b}$ shows the locations of strain gauges on concrete, steel and CFRP sheets and plates. All beams were loaded monotonically using a digitally controlled INSTRON 8806 Universal Testing Machine (UTM) as in Figure 6. The UTM has a capacity of $2500 \mathrm{kN}$ and the member were tested under a load control rate of $10 \mathrm{kN} / \mathrm{min}$. All experiments were conducted at room temperature and at room humidity, consistently.

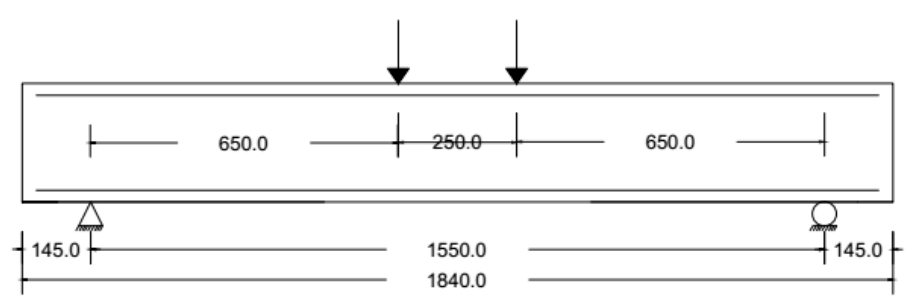

(a)

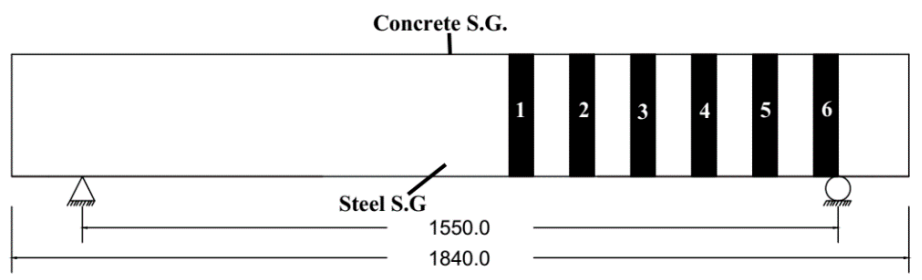

(b)

Figure 5. Test setup and instrumentations (all dimensions are in $\mathrm{mm}$ ): (a) Loading setup; (b) Strain gauges location.

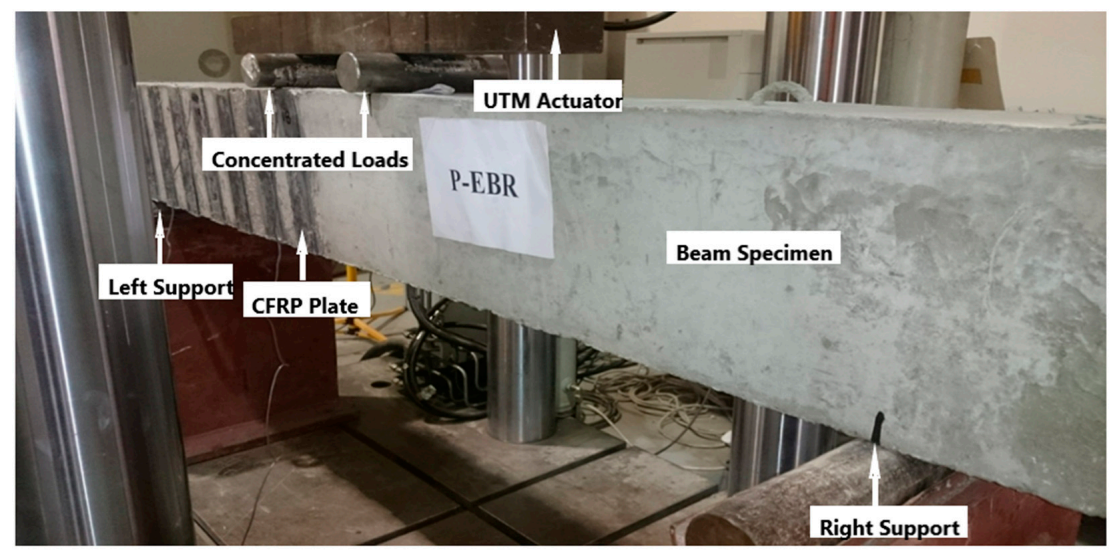

Figure 6. Test specimen mounted in the universal testing machine. 


\section{Experimental Results and Discussion}

\subsection{Summary of Experimental Results}

This section includes the results of the experimental program conducted in this investigation. As indicated, all the samples were tested under four point bending and the applied force and corresponding deflection at the beams' mid span were recorded and plotted, strain graphs of the data recorded from strain gauges (concrete, steel and CFRP) are shown for each beam. In addition, captions of the failed beam specimens are provided to demonstrate the modes of failure. Table 3 presents summary of the experimental results in terms of ultimate attained load, corresponding deflection at mid span and the percentage increase over the control beam with the associated failure mode for each beam specimen.

Table 3. Summary of experimental results.

\begin{tabular}{|c|c|c|c|c|c|c|}
\hline No & Specimen & Load (kN) & Deflection $(\mathrm{mm})$ & $\begin{array}{c}\text { Increase over } \\
\text { Control Beam (\%) }\end{array}$ & $\begin{array}{c}\text { Increase over } \\
\text { EBR Beams (\%) }\end{array}$ & Failure Mode \\
\hline 1 & C & 116.96 & 5.24 & - & - & Major shear crack \\
\hline 2 & P-EBR & 162.90 & 7.10 & 39.3 & - & $\begin{array}{l}\text { Major shear crack + } \\
\text { CFRP debonding }\end{array}$ \\
\hline 3 & PGT & 241.68 & 8.77 & 106.6 & 48.4 & $\begin{array}{l}\text { Major shear crack }+ \\
\text { CFRP delamination }\end{array}$ \\
\hline 4 & PGM & 248.30 & 7.79 & 112.4 & 52.4 & $\begin{array}{l}\text { Major shear crack + } \\
\text { CFRP delamination }\end{array}$ \\
\hline 5 & PGD & 176.30 & 7.72 & 50.7 & 8.2 & $\begin{array}{l}\text { Major shear crack }+ \\
\text { CFRP delamination }\end{array}$ \\
\hline 6 & S-EBR & 190.04 & 5.85 & 62.5 & - & $\begin{array}{l}\text { Major shear crack + } \\
\text { CFRP debonding }\end{array}$ \\
\hline 7 & SGT & 240.60 & 7.35 & 105.7 & 26.6 & $\begin{array}{l}\text { Major shear crack }+ \\
\text { CFRP delamination }\end{array}$ \\
\hline 8 & SGM & 281.89 & 10.93 & 141.0 & 48.3 & $\begin{array}{l}\text { Major shear crack + } \\
\text { CFRP delamination }\end{array}$ \\
\hline 9 & SGD & 214.56 & 8.85 & 83.5 & 12.9 & $\begin{array}{l}\text { Major shear crack }+ \\
\text { CFRP delamination }\end{array}$ \\
\hline
\end{tabular}

\subsection{Load Deflection Relationships and Modes of Failure}

\subsubsection{Specimens C, S-EBR and P-EBR}

The control beam failed in shear as expected with a capacity of $116.96 \mathrm{kN}$. As shown in Figure 7a, the shear crack took place in the half of the unreinforced side of the beam with shear reinforcement (stirrups), it started from the point of load application and propagated to the support of the beam at an angle of approximately 45 degrees. This failure mode is expected since the a/d is 2.51 , which is between 2.5 and 5 .

The S-EBR beam was strengthened in shear with CFRP sheets using EBR method. This beam specimen failed in shear with a diagonal tension crack experiencing higher load and displacement compared to the control beam. The ultimate load sustained by S-EBR was $190.04 \mathrm{kN}$, which is $62.5 \%$ higher than the control beam, with a corresponding maximum deflection of $8.85 \mathrm{~mm}$. At the onset of failure, diagonal cracks were formed and passed under CFRP sheets number 2 and 3 and sudden debonding of these sheets took place as shown in Figure $7 \mathrm{~b}$. This occurred mainly due to the weak interface between the CFRP sheets and concrete beam.

The P-EBR beam was strengthened in shear with CFRP plates using EBR method. This beam specimen failed in shear with a diagonal tension crack experiencing higher load and displacement compared to the control beam. The ultimate load was $162.90 \mathrm{kN}$, which is $39.3 \%$ higher than the control beam, with an associated deflection of $7.10 \mathrm{~mm}$. At the onset of failure, a diagonal crack was formed and passed under CFRP sheets number 2 and 3, then sudden debonding of CFRP plates happened and that is also due to the weak interface between the CFRP plates and concrete beam as shown in Figure $7 \mathrm{c}$. 


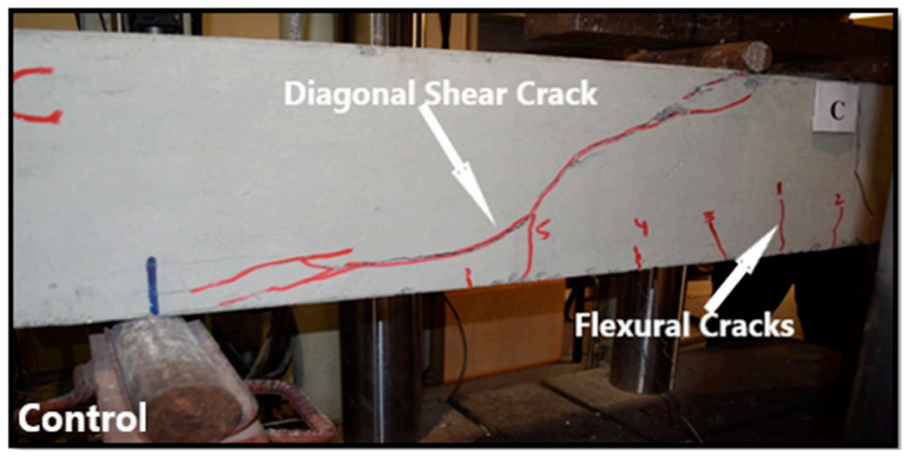

(a)

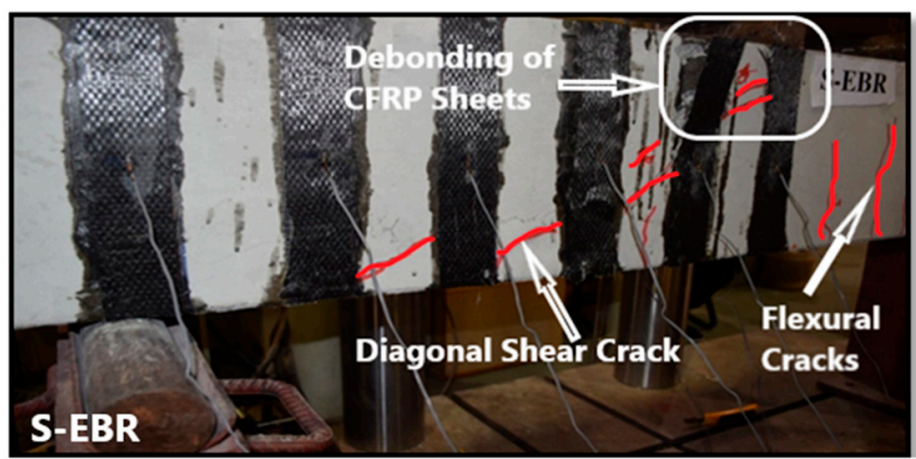

(b)

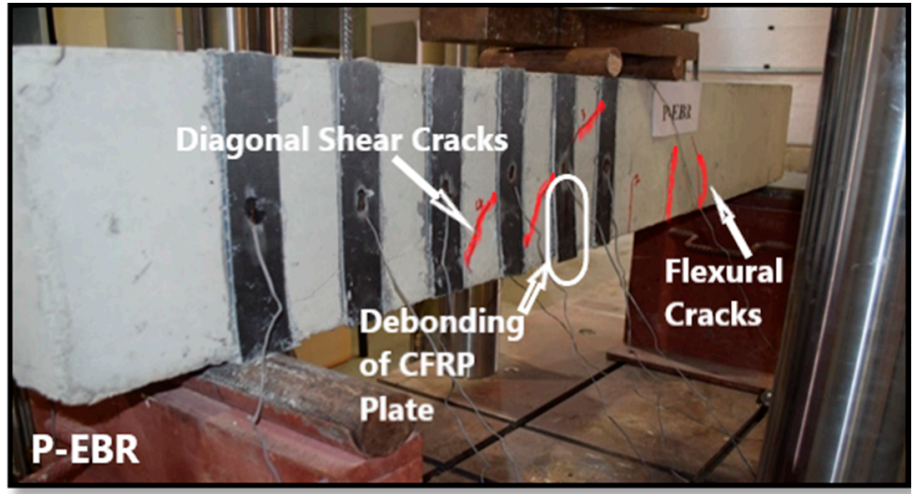

(c)

Figure 7. Failure modes: (a) Diagonal shear crack on the control beam; (b) debonding of CFRP sheets in S-EBR; (c) debonding of CFRP plates in P-EBR.

\subsubsection{Specimens PGT, PGM and PGD}

The PGT beam was strengthened in shear with CFRP plates using groove-epoxy anchorage with two thin grooves. It failed in shear with a diagonal tension crack experiencing higher load and displacement compared to control beams. The ultimate load was $241.68 \mathrm{kN}$ with a deflection of $8.77 \mathrm{~mm}$, which is $106.63 \%$ higher than the control beam as shown in Table 3. At the onset of failure, diagonal crack passed under CFRP plate number 2 and 3 and delamination of CFRP plate number 2 happened, as shown in Figure 8a. The PGM beam was strengthened in shear with CFRP plates using groove-epoxy anchorage with two medium grooves. It failed in shear with a diagonal tension crack experiencing higher load and displacement compared to the control beam. The ultimate load was $248.30 \mathrm{kN}$ with a deflection of $7.79 \mathrm{~mm}$ (Table 3), which is $112.29 \%$ higher than the control beam. It also showed larger attained load than the PGT sample, which means that the groove width has an effect in delaying debonding. At last, because of the weak interface between the CFRP plates and 
concrete beam, diagonal crack passed under CFRP plate number 2 and 3 and delamination of CFRP plate number 2 happened as shown in Figure 8b. The PGD beam was strengthened in shear with CFRP plates using groove-epoxy anchorage with one dense groove. It failed in shear with a crack that started from the load point and went through the top of the beam until it reached the third CFRP plate, then it went down diagonally and continued through the bottom until it reached the beam's edge, experiencing higher load and displacement compared to the control beam. The ultimate load was $176.30 \mathrm{kN}$ with an associated deflection of $7.72 \mathrm{~mm}$ (Figure 8), which is $50.74 \%$ only higher than the control beam but less than PGT and PGM. Thus, two thin or medium groves performs better than one dense groove in delaying plate debonding. Eventually, delamination of CFRP plates 2 and 3 happened, as shown in Figure 8c.

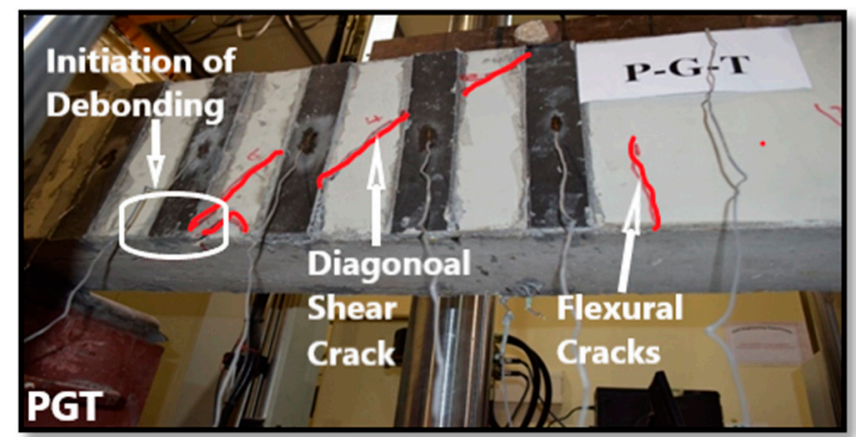

(a)

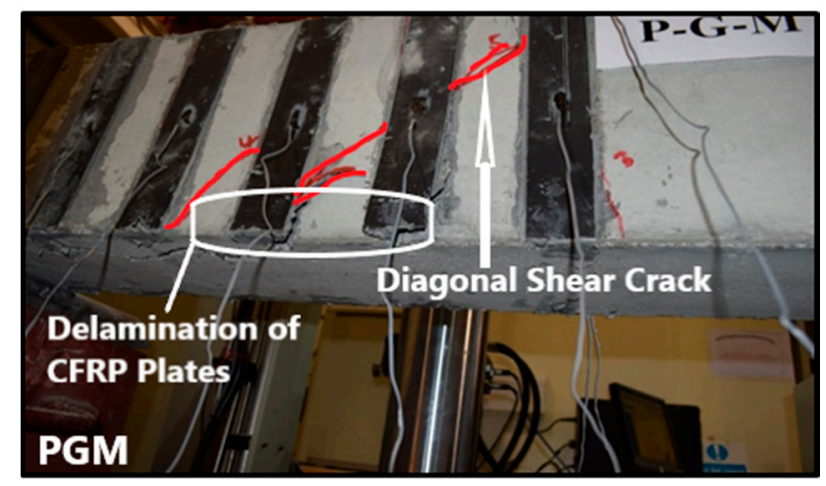

(b)

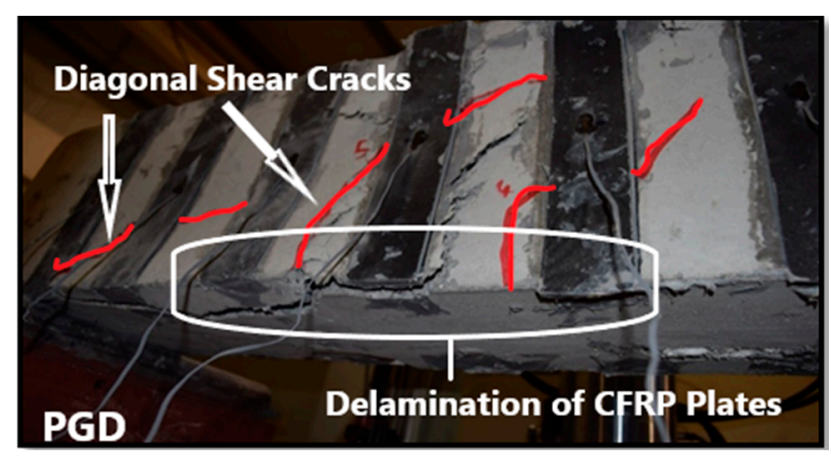

(c)

Figure 8. Failure modes: (a) PGT beam; (b) PGM beam; (c) PGD beam.

Figure 9 shows the load-deflection relationship for the beams with groove-epoxy anchorage systems using CFRP plates (PGT, PGM and PGD). The thin and medium grooves achieved the maximum load and slightly more deflection among the three specimens that were strengthened 
with groove-epoxy, as shown in Figure 9. All the beams that used groove-epoxy anchorage systems consistently showed higher strength than that of the conventional EBR strengthening method.

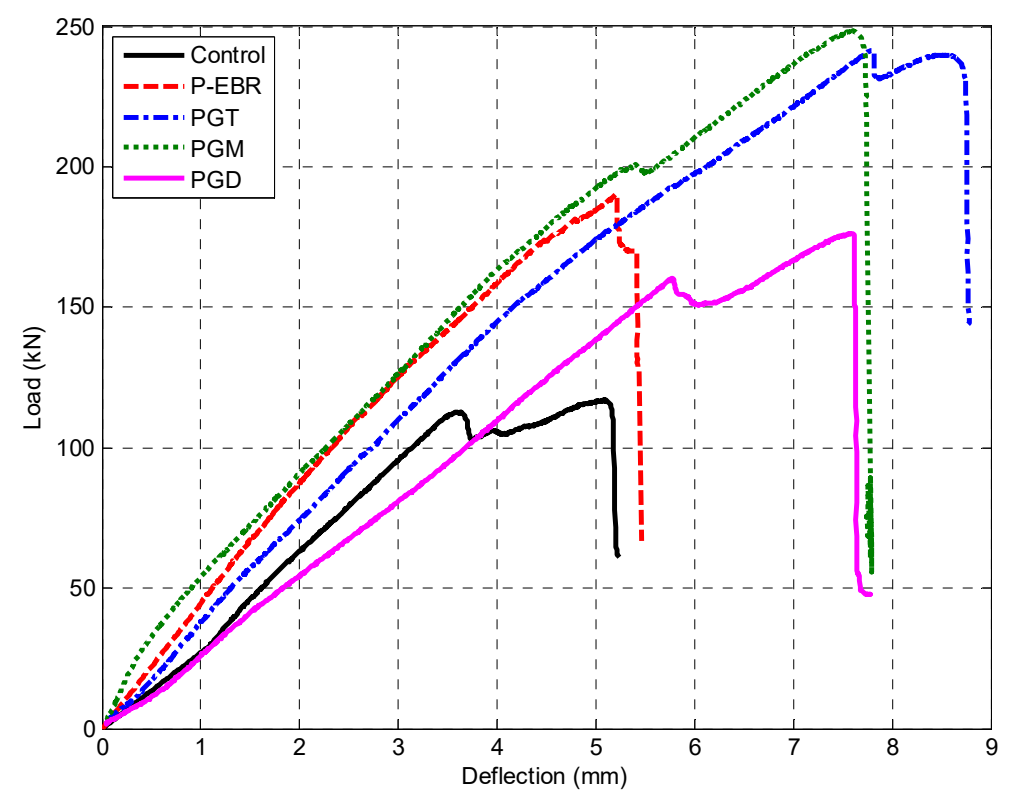

Figure 9. Load deflection curves for PGT, PGM, and PGD beam.

\subsubsection{Specimens SGT, SGM and SGD}

The SGT beam was strengthened in shear with CFRP sheets using groove-epoxy anchorage with two thin grooves. It failed in shear with a crack started from the load point and going down until the third CFRP sheet and then continued through the beam bottom until it reached the edge experiencing higher load and displacement compared to control beams. The ultimate load was $240.60 \mathrm{kN}$ with deflection of $7.35 \mathrm{~mm}$ (Table 3) which is $105.71 \%$ higher than the control beam. It's observed that the thin groove-epoxy anchors helped in delaying the debonding of CFRP sheets. At last, diagonal crack passed under CFRP plate numbers 2 and 3 and delamination of CFRP sheet number 2 happened as in Figure 10a. The SGM beam was strengthened in shear with CFRP sheets using groove-epoxy anchorage with two medium grooves. It failed in shear with a crack started from the load point and going down after the second sheet and started going down diagonally until the third CFRP sheet then continues through the beam bottom until it reached the edge experiencing higher load and displacement compared to control beams. The ultimate load was $281.89 \mathrm{kN}$ with deflection of $10.93 \mathrm{~mm}$ (Table 3) which is $141.01 \%$ higher than the control beam. It can be noticed that the medium groove-epoxy anchors helped in considerably delaying the debonding of CFRP sheets. Ultimately, delamination of the second and third CFRP sheet happened, as shown in Figure 10b. The SGD beam was strengthened in shear with CFRP sheets using groove-epoxy anchorage with one dense groove. It failed in shear with a crack that started from the load point and went through the top of the beam causing the first and third CFRP sheets to delaminate, then it passed diagonally to the bottom, and continued through the bottom until it reached the beam's edge experiencing higher load and displacement compared to the control beam. The ultimate attained load was $214.56 \mathrm{kN}$ with a deflection of $8.85 \mathrm{~mm}$, as depicted in Figure 11, which is $83.45 \%$ higher than the control beam. It can be noticed that the dense groove-epoxy anchors helped in delaying the debonding of CFRP sheets. At last, some sheets were delaminated as shown in Figure 10c.

Figure 11 shows load and deflection relationship for the beams with groove-epoxy anchorage strengthening method using CFRP sheets (SGT, SGM and SGD). The sheets with medium grooves achieved the highest attained load along with the highest associated deflection among the three specimens, which proved that there is an optimum size for the groove's effectiveness. 
Nevertheless, all the beams that used groove-epoxy anchorage system achieved higher strength compared to the beam with conventional EBR method.

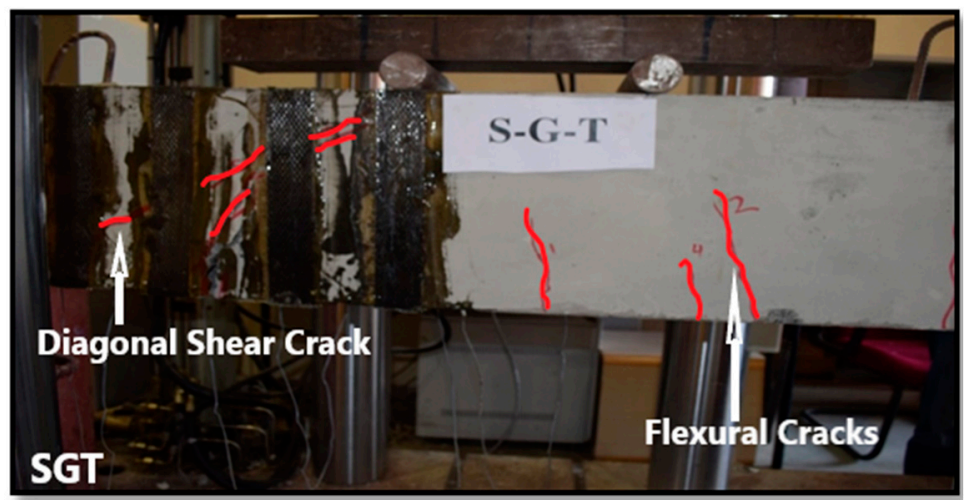

(a)

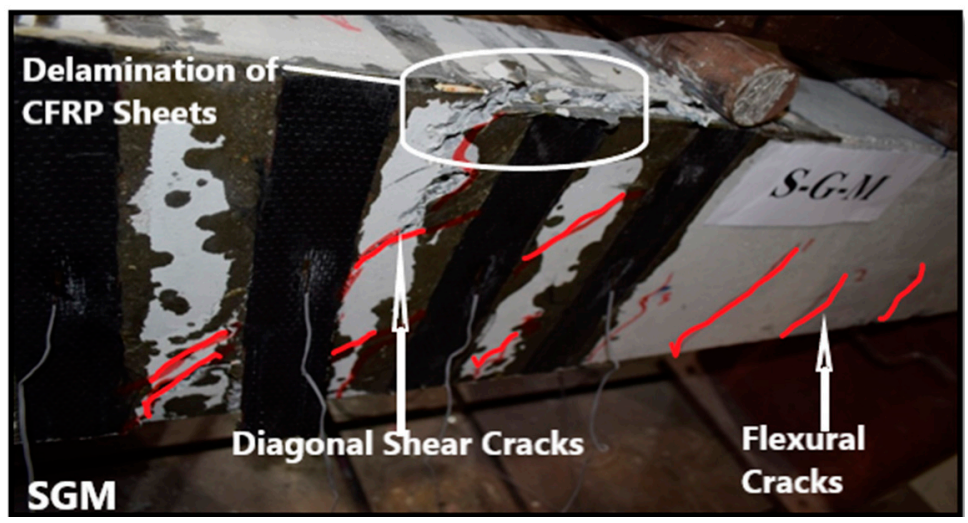

(b)

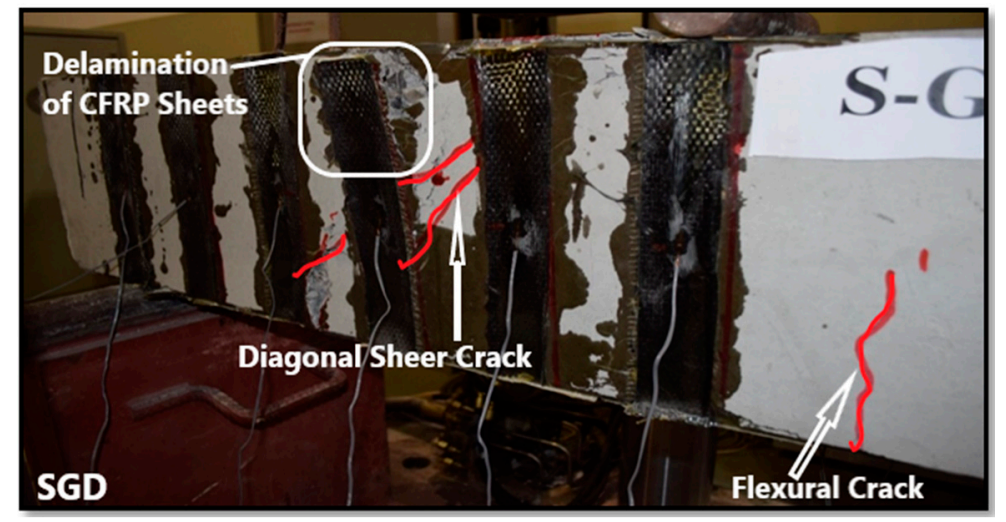

(c)

Figure 10. Failure modes: (a) SGT beam; (b) SGM beam; (c) SGD beam.

Figure 12 shows the effect of groove width on the shear capacity of RC beams. Overall, the groove-epoxy anchorage system with CFRP sheets on medium groove size shows the highest ultimate shear load capacity and highest deflection compared to all tested specimens as shown in Figure 12c. It is also observed from Figure 12b that for the beams strengthened with EBR on thin grooves, the stiffness of beams strengthened with plates and sheets is the same and the ultimate shear capacity is also quite similar with a slight difference in the ultimate displacement. The medium grooves showed a larger shear capacity than the thin and the dense grooves. This suggested that there 
is an optimum groove width for the given groove depth that is close to the medium width. As the width of grooves increases (dense grooves) the case resembles an EBR with deep epoxy only, while as the thickness of grooves decreases (thin grooves), the effectiveness of grooves diminishes due to the decrease in groove width that is in contact with the plate or the sheet, which results in a case that resembles an EBR.

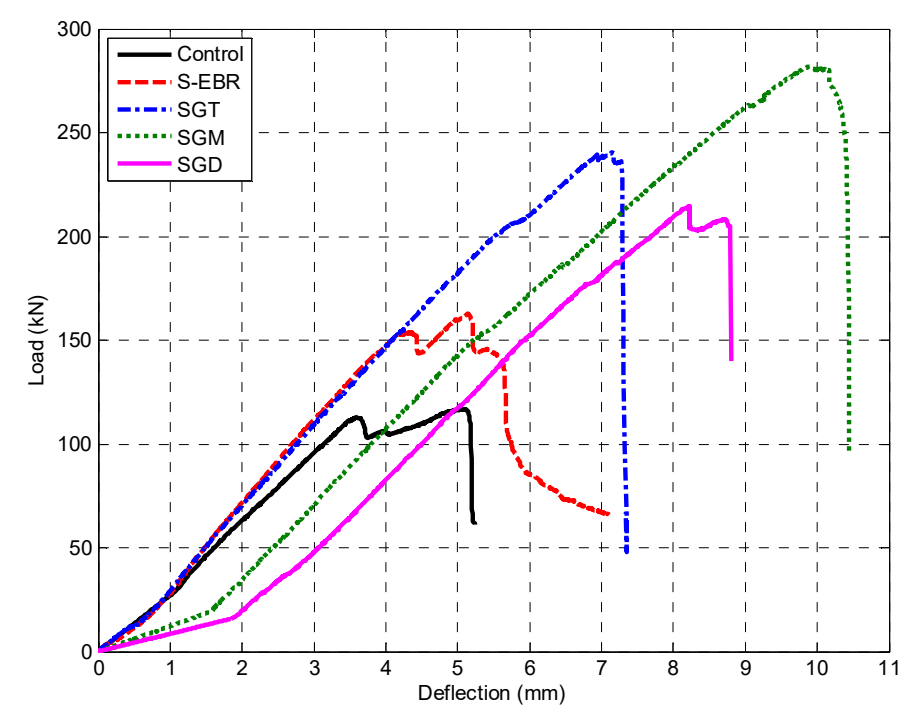

Figure 11. Load deflection curves for SGT, SGM, and SGD beam.

(a) Control, P-EBR, S-EBR

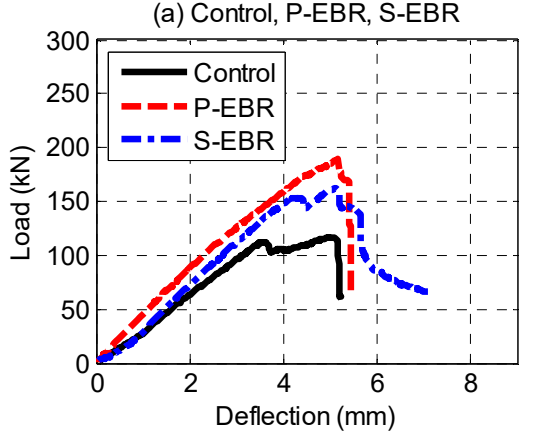

(c) Medium Groove

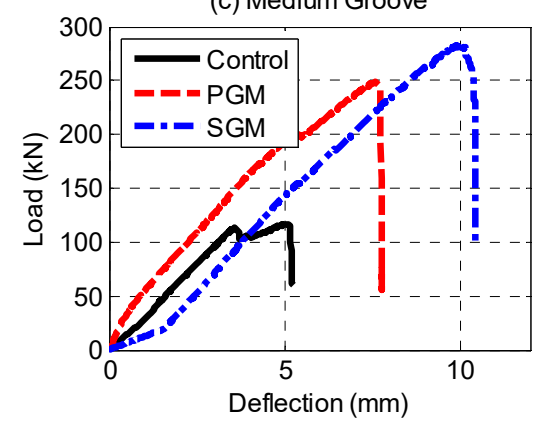

(b) Thin Groove

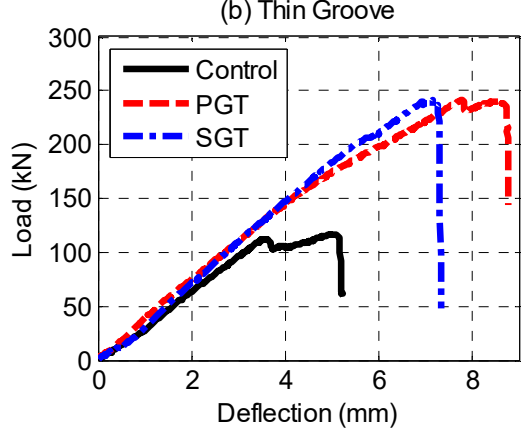

(d) Dense Groove

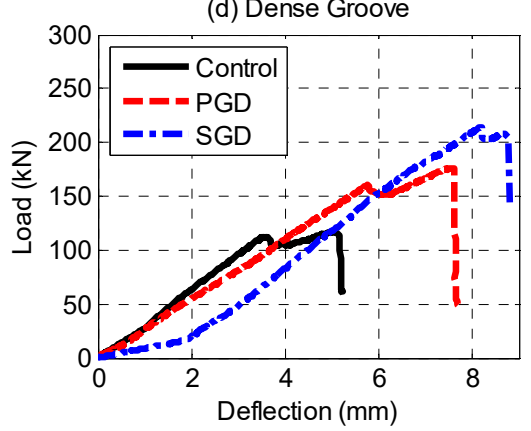

Figure 12. Load-deflection curves: (a) Control, P-EBR, S-EBR; (b) Thin grooves; (c) Medium grooves; (d) Dense grooves.

In summary, all specimens failed in shear with a major diagonal shear crack followed by CFRP sheets or plates debonding or delamination and some flexural cracks or flexural-shear cracks. Crushing of concrete at the point of application of the load took place for some specimens. Although all failures were brittle shear failure, however, the use of groove epoxy delayed the debonding of CFRP laminates and therefore increased the shear capacity of the strengthened beams. The appearance of small flexural 
and flexural-shear cracks had little contribution, if any, to the brittle shear failure of the tested beams. At the onset of failure, diagonal shear cracks usually pass under the CFRP plates or sheets. Even for the debonding failure mode, it took place at a higher strain level, but still below the CFRP rupture's strain.

\section{Load Strain Relationships}

Table 4 display the recorded strain values for concrete, steel, and CFRP sheets and plates for all the beams during testing.

Table 4. Summary of experimental results.

\begin{tabular}{ccccc}
\hline No. & Specimen & $\begin{array}{c}\text { Maximum Strain } \\
\text { in Concrete }(\mu \mathbf{s})\end{array}$ & $\begin{array}{c}\text { Maximum Strain } \\
\text { in Steel }(\mu \mathbf{s})\end{array}$ & $\begin{array}{c}\text { Maximum Strain in } \\
\text { CFRP Laminates }(\mu \mathbf{s})\end{array}$ \\
\hline 1 & C & 1046.0 & 1044 & - \\
2 & P-EBR & 1155.8 & 1390.9 & 1895.8 \\
3 & PGT & 3073.1 & 2388.0 & 1133.7 \\
4 & PGM & 2154.2 & 1930.3 & 873.5 \\
5 & PGD & 1248.9 & 1390.9 & 2456.5 \\
6 & S-EBR & 1027.8 & 1709.9 & 4740.4 \\
7 & SGT & 1987.6 & 2438.9 & 4697.2 \\
8 & SGM & 2360.0 & 5077.7 & $15,834.0$ \\
9 & SGD & 1498.9 & 1983.7 & 7800.9 \\
\hline
\end{tabular}

Figure 13a,b show the load versus microstrain response curves for the concrete of all tested samples. The maximum strain reached by concrete is less than the crushing value of concrete. Figure 13c,d show the load-strain for steel in the RC beams strengthened with plates and sheets, respectively. It is clear that the maximum strain reached by the flexural steel reinforcement is less than the yielding value for steel, confirming that the steel did not yield.
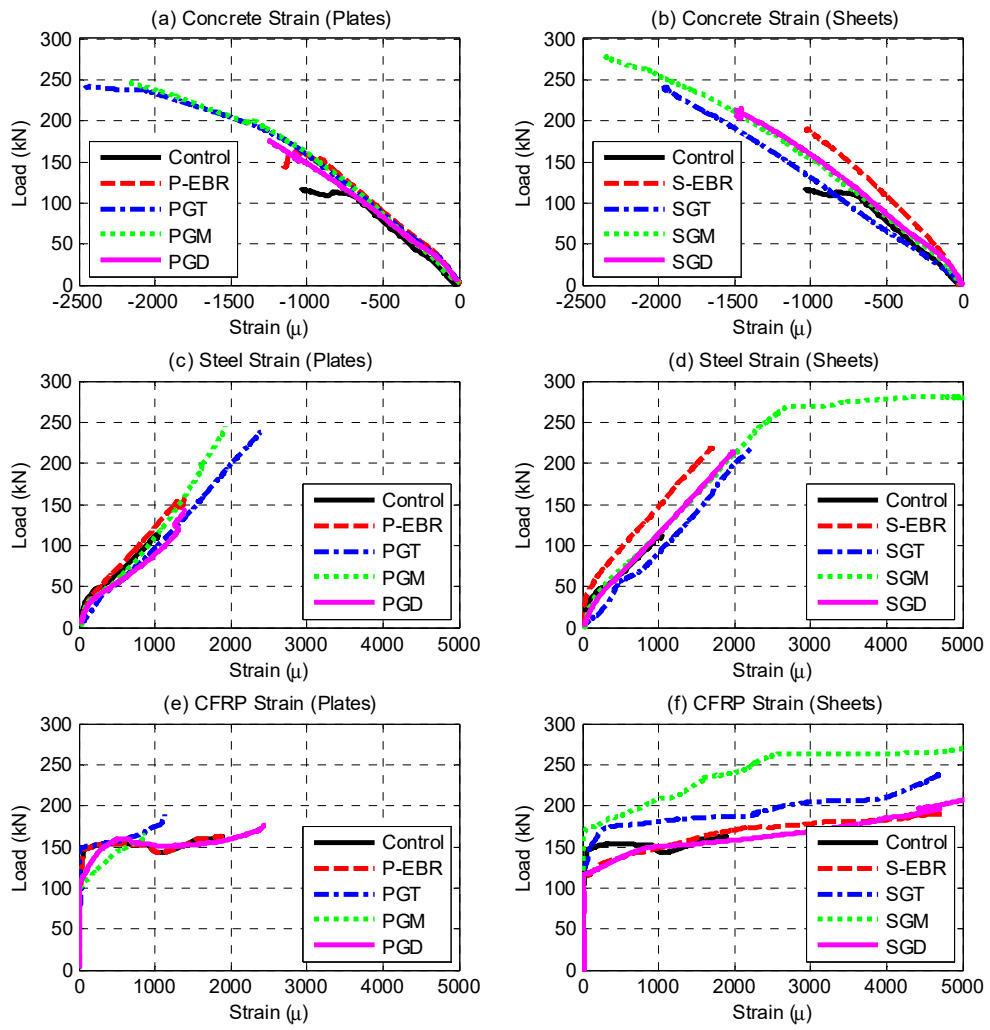

Figure 13. Load-strain relationships for concrete, steel and CFRP laminates: (a) Concrete strain (Plates); (b) Concrete strain (Sheets); (c) Steel strain (Plates); (d) Steel strain (Sheets); (e) CFRP strain (Plates);

(f) CFRP strain (Sheets). 
As previously indicated, six strain gauges were attached to the CFRP sheets to record the strain while applying the load in each of the beams P-EBR, PGT, PGM, and PGD, and were attached at the center of every CFRP sheet. They showed a maximum microstrain of 4740.4, 4697.2, 15,834.0, and 7800.9 which represents $23.7 \%, 23.5 \%, 79.2 \%$, and $39.0 \%$ of the ultimate strain of the CFRP sheets $(20,000)$ as shown in Figure 13e. These strain values proved that the groove-epoxy system increased the strain in the CFRP sheets. Six strain gauges were attached to the CFRP plates to record the strain while applying the load in each of the beams S-EBR, SGT, SGM and SGD, and were attached at the center of every CFRP plate. They showed maximum microstrain values of 1895.8, 1133.7, 873.5, and 2456.5 which represents $9.5 \%, 5.7 \%, 4.4 \%$, and $12.3 \%$ of the ultimate strain of the CFRP plates $(20,000)$ as shown in Figure 13f. These strain values proved that groove-epoxy system increased the strain in the CFRP plates as well.

\section{Models for Prediction of Shear-Strength of Groove-Epoxy Anchorage}

\subsection{ACI440.2R Prediction of Shear-Strength Capacity of RC Beams}

ACI 440.2R-17 [54] presents guidelines for using FRP in flexure and shear applications. These guidelines are based on a limit-states-design that sets limits on both serviceability and ultimate limit states. The deboning failure mode (brittle failure mode) takes place at a strain level below the FRP rupture strain. The ACI specified a maximum attainable strain of $0.4 \%$ in the FRP wraps which have been adopted from Khalifa et al. [55] who proposed a maximum strain limit of $0.4 \%$ to maintain the shear integrity of the concrete and prevent loss of aggregate interlock. For completely wrapped elements: the effective strain level in FRP reinforcement attained at failure $\varepsilon_{\mathrm{fe}}=0.004 \leq 0.75 \varepsilon_{\mathrm{fu}}$. However, for U-wraps and side applications the ACI guidelines introduce a bond-reduction coefficient $\mathrm{K}_{\mathrm{v}}$, as such FRP applications are susceptible to the debonding failure mode. The bond reduction coefficient $\mathrm{K}_{\mathrm{v}}$ that was experimentally derived is dependent upon several factors, including concrete strength, type of wrapping scheme used, and stiffness of the FRP laminate. The following equations were used in predicting the shear strength of the tested specimens.

$$
\phi V_{n}=\phi\left(V_{c}+V_{s}+\Psi V_{f}\right)
$$

where $V_{c}, V_{s}$, and $V_{f}$ are the shear strength contribution of concrete, stirrups, and FRP, respectively.

\subsection{Proposed Model for Predicting Shear Capacity of CFRP Plate on Groove-Epoxy}

From the experimental results two empirical shear capacity prediction models have been developed, one for CFRP plates and the other for CFRP sheets mounted on groove-epoxy system. The models are based on a groove factor $G_{F P}$ for plates or $G_{F S}$ for sheets. This factor incorporates the shear-strength contribution due to the use of grooves in the shear-strength contribution of the FRP (i.e., $V_{f}$ ) of ACI440.2R-17 [54] shear prediction equation. The groove factors $\left(G_{F P}\right.$ or $\left.G_{F S}\right)$ are defined as the ratio of the shear-strength contribution of RC beam strengthened with CFRP plates/sheets on groove-epoxy over the shear-strength contribution of CFRP as EBR without groove-epoxy.

The nominal shear capacity of the RC beam strengthened with CFRP plates on groove-epoxy, including contributions of concrete, steel reinforcement and FRP reinforcement, is given by Equation (2). This is the ACI440.2R-17 [54] equation that has been modified by including a Groove Factor $\left(G_{F P}\right.$ or $\left.G_{F S}\right)$ to the shear-strength contribution of the FRP. The groove factor $G_{F P}$ for CFRP plate is given by Equation (3) and its variation with groove width is shown in Figure 14. The average mean absolute percent error (MAPE) for prediction MAPE $=6.04 \%$, normalized mean square error (NMSE) NMSE $=0.072$, and coefficient of determination $R^{2}=0.964$.

$$
V_{n}=V_{c}+V_{s}+G_{F P} \Psi_{f} V_{f}
$$


where:

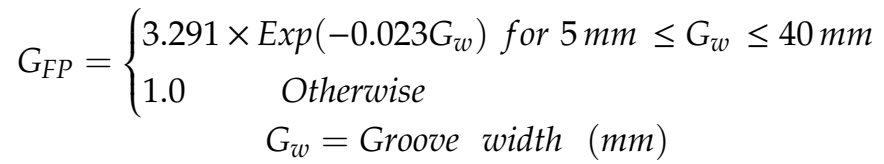

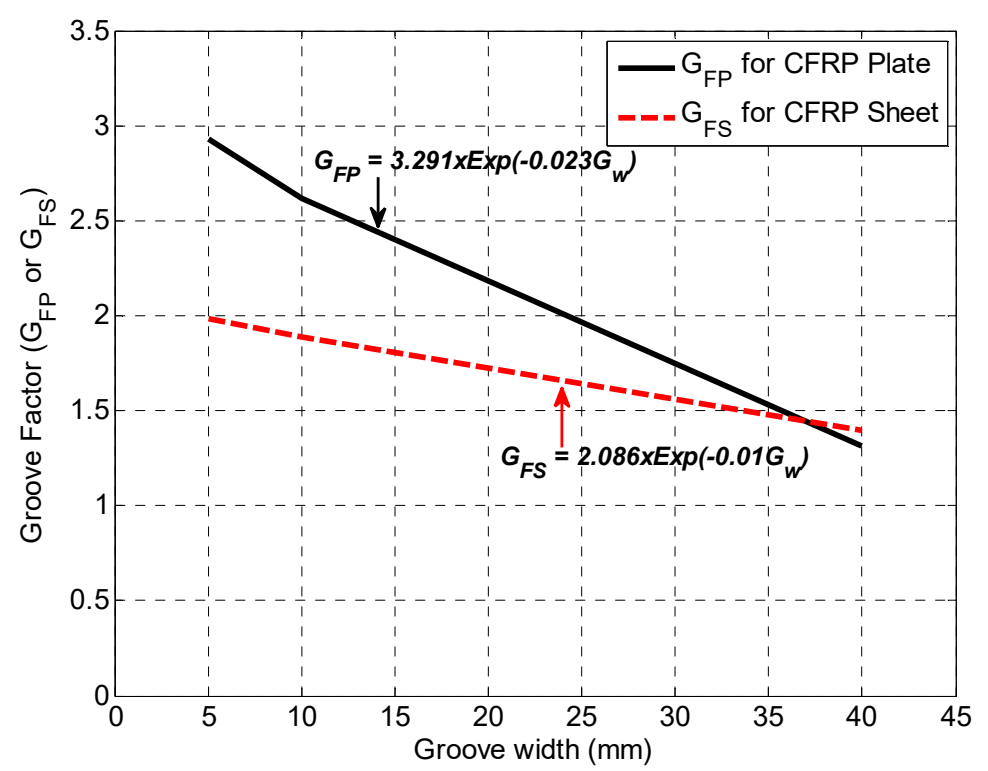

Figure 14. Groove Factors (GFP and GFS) for CFRP plats and sheets on groove-epoxy.

\subsection{Model for Predicting Shear Capacity of CFRP Sheet on Groove-Epoxy}

The nominal shear capacity of the RC beam strengthened with CFRP sheets on groove-epoxy is given by Equation (4) and the groove factor for CFRP sheets is given by Equation (5) and also depicted in Figure 14. The average MAPE $=12.79 \%$, NMSE $=0.525$ and $R^{2}=0.689$.

$$
V_{n}=V_{c}+V_{s}+G_{F S} \Psi_{f} V_{f}
$$

where:

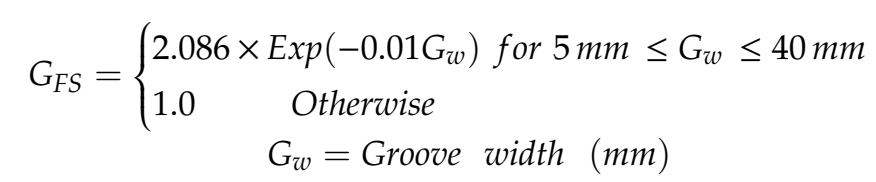

Table 5 illustrates the experimental shear strength $\left(\mathrm{V}_{\exp }\right)$ and the theoretical shear strength at different strain levels. ACI equations use $\left(\mathrm{K}_{\mathrm{v}} \times \varepsilon_{\mathrm{fu}}\right)$ as a limit for the strain used to predict the shear strength. The shear strength is also calculated using the strain values obtained from the CFRP strain gauges. All these predicted values were less than the experimental ones, therefore, higher strain values were used to calculate the shear strength (3000 and $6000 \mu$ strain). Figure 15 represents the experimental and the model predicted shear strength values for P-EBR, GT, PGM, and PGD beams as well as those using the ACI equation with strain limit. It has been observed that the actual shear strength valued falls between strain values of 3000 to $6000 \mu$ strain, which means that the ACI limit $\left(K_{v} \times \varepsilon_{f u}\right)$ needs to be adjusted when using the groove-epoxy anchorage system with CFRP plates. 
Table 5. Measured and predicted loads for RC beam strengthened with CFRP plates on groove-epoxy.

\begin{tabular}{cccccc}
\hline Designation & $\begin{array}{c}\text { Experimental } \\
\mathbf{( k N )}\end{array}$ & $\begin{array}{c}\text { ACI-440 Strain } \\
\text { Limit (kN) }\end{array}$ & $\begin{array}{c}\text { Groove-Epoxy Model } \\
\text { (Equation (2)) } \\
(\mathbf{k N})\end{array}$ & $\begin{array}{c}\text { ACI-440 MAPE } \\
\mathbf{( \% )}\end{array}$ & $\begin{array}{c}\text { Model MAPE } \\
\mathbf{( \% )}\end{array}$ \\
\hline C & 117.0 & 114.28 & - & - & - \\
P-EBR & 162.9 & 160.4 & 160.4 & 1.53 & 1.53 \\
PGT & 241.7 & 154.321 & 252.194 & 36.15 & 4.35 \\
PGM & 248.3 & 154.892 & 237.503 & 37.62 & 4.36 \\
PGD & 176.3 & 161.797 & 177.421 & 8.25 & 0.61 \\
\hline
\end{tabular}

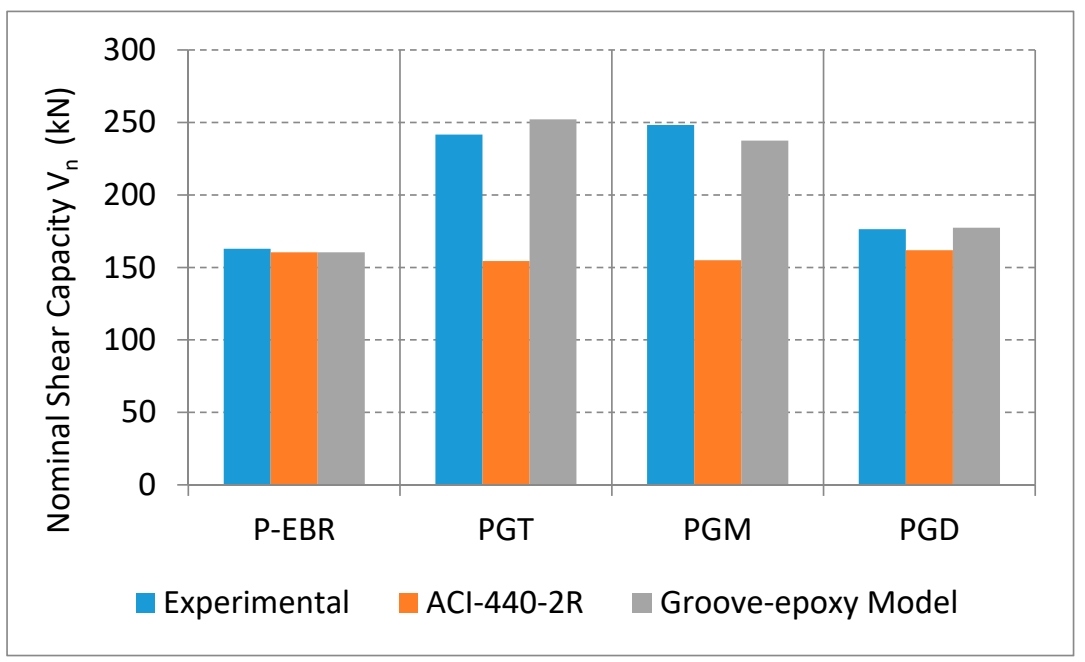

Figure 15. Comparison of measured and predicted shear capacity for RC beams strengthened with CFRP plates on groove-epoxy.

Table 6 illustrates the experimental, the ACI and the model predicted shear strength values. The ACI value was based on the imposed strain limit of $K_{v} \times \varepsilon_{f u}$. It is observed that the predicted values were less than the experimental ones, therefore, higher strain values were used to calculate the shear strength (2500 and $4500 \mu$ strain). Figure 16 represents the experimental and the model predicted shear strength values for S-EBR, SGT, SGM, and SGD beams as well as the ACI ones using the ACI equation with the strain limit. It can be deduced that the actual shear strength values falls between strain values of 2500 and $4500 \mu$ strain, which means that the $A C I$ limit $\left(K_{v} \times \varepsilon_{f u}\right)$ needs to be increased when using groove-epoxy anchorage system with CFRP sheets. Therefore, the proposed models, with groove-epoxy factors, could be used to predict the shear capacity of the strengthened specimens with a reasonable level of accuracy.

Table 6. Measured and predicted loads for RC beam strengthened with CFRP sheets on groove-epoxy.

\begin{tabular}{cccccc}
\hline Designation & $\begin{array}{c}\text { Experimental } \\
(\mathbf{k N})\end{array}$ & $\begin{array}{c}\text { ACI-440 Strain Limit } \\
\mathbf{( k N )}\end{array}$ & $\begin{array}{c}\text { Groove-Epoxy Model } \\
\text { (Equation (4)) } \mathbf{( k N )}\end{array}$ & $\begin{array}{c}\text { ACI-440 MAPE } \\
\mathbf{( \% )}\end{array}$ & $\begin{array}{c}\text { Groove-Epoxy Model MAPE } \\
(\%)\end{array}$ \\
\hline C & 117.0 & 114.28 & - & - & - \\
S-EBR & 190.04 & 131.9 & 131.0 & 30.59 & 30.59 \\
SGT & 240.62 & 127.3 & 261.970 & 47.10 & 8.15 \\
SGM & 281.89 & 126.5 & 254.898 & 55.12 & 10.59 \\
SGD & 214.57 & 136.9 & 219.147 & 36.20 & 2.099 \\
\hline
\end{tabular}

As previously indicated, the groove-epoxy anchorage system, also known as EBROG, has been used mainly for anchoring FRP for flexural strengthening and it was very successful in delaying debonding and therefore improving the flexural capacity of the strengthened RC beam specimens. Very little work had been attempted in using groove-epoxy in anchoring FRP for shear strengthening of RC beams with practical dimensions. Experimental programs that used small-size RC beams (prisms) with dimensions of $70 \times 85 \times 560 \mathrm{~mm}$ [45] and $70 \times 85 \times 570 \mathrm{~mm}$ [46], explored the use of groove-epoxy or ERBOG on anchoring of CFRP sheets for shear strengthening [45,46]. They concluded 
that EBROG method is a very efficient technique in increasing the shear capacity of the tested small-size beams by up to $23 \%$ over unstrengthened control beam for one layer of CFRP sheet. In this study large-size RC beams with dimensions of $200 \times 300 \times 1840 \mathrm{~mm}$ were tested and the increase in shear capacity reached up to $141 \%$ over the unstrengthened control beam. It is clear that the results of both experimental investigations showed an increase in the shear capacity of the tested specimens, however, the strengthened specimens and the size effect may have contributed to the variation of percent increase in the shear capacity.

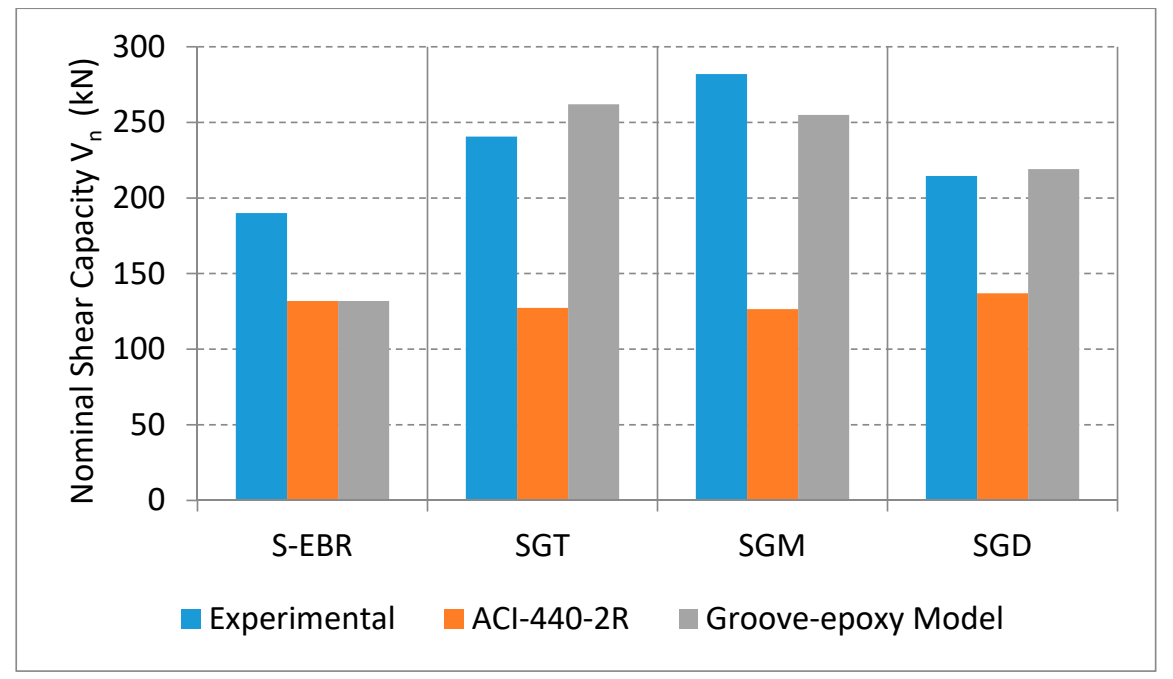

Figure 16. Comparison of measured and predicted shear capacity for RC beams strengthened with CFRP sheets on groove-epoxy.

Several researchers have thoroughly investigated the size effect on the shear strength and shear failure mode of RC beams and thus identified several parameters that have different level of influence on the size effect [56-63]. Such parameters included shear-span-to-depth ratio (a/d), beam depth (d), maximum aggregate size, and concrete strength $\left(\mathrm{fc}_{\mathrm{c}}\right)$, among others. It was observed that using small size specimens may lead to overestimation of shear strength of beams without stirrups. The beam specimens tested in this investigation did not have stirrups on one side and they all failed in shear with a major diagonal shear crack that propagated until failure. The "a/d" ratio of all tested beams has been kept at a constant value of 2.51 to ensure shallow (slender) beam behavior. Since all beams failed in shear, there is a strong size effect on the experimental values of the shear strength of the tested beams and also on the brittleness of their failure mode. Such size effect should be taken into consideration when comparing the experimentally measured shear strength values of this investigation to those of beams with larger sizes.

\section{Summary and Conclusions}

In this study the problem of early debonding of CFRP sheets and plates has been addressed, when used in shear strengthening application of reinforced concrete beams. It can be concluded from this investigation that:

1. Using the EBR conventional method showed an increase in the shear capacity over the control beam by $39.28 \%$ and $62.48 \%$ for CFRP plates and sheets strengthened specimens, respectively.

2. When CFRP plates are used, groove-epoxy anchors had increased the shear capacity up to $112.29 \%$ over the control beam and 52.42\% over the EBR strengthened beam. While CFRP sheet specimens showed an increase of 141.01 and $48.36 \%$ over the control and EBR strengthened specimens, respectively. 
3. The groove-epoxy anchorage system increased the shear-strength contribution of CFRP without grooves in the range of $30-190 \%$ for CFRP plates and $40-100 \%$ for CFRP sheets.

4. Generally, the contributions of groove-epoxy on shear-strength decreases with the increase of groove width, with the medium groove specimens showed the best performance among the other groove sizes.

5. All specimens failed in shear with a major diagonal shear crack, followed by CFRP sheets or plates debonding, or delamination and some combination of small flexural and flexural-shear cracks.

6. The groove-epoxy method changed the mode of failure from debonding to delamination for almost all specimens and delayed the early debonding failure of CFRP sheets and plates for others, and consequently increased the beams' shear strength and maximum deflection.

7. The developed shear-strength prediction models incorporated groove factors as a modifier to the FRP shear-strength contribution of ACI-440 shear equation. The developed models predicted the experimental shear-strength of RC beams with the utilized groove-epoxy systems with a good level of accuracy, with an average MAPE $=3.31 \%$ and $6.68 \%$, NMSE $=0.072,0.523$ and coefficient of determination $\mathrm{R}^{2}=0.964,0.691$, for plates and sheets, respectively.

Author Contributions: Conceptualization, K.M.; Methodology, K.M.; Formal analysis and investigation, J.A.A., K.M.; Supervision, J.A.A. and R.A.H.; Writing-original draft preparation, K.M.; writing-review and editing, J.A.A. and R.A.H.; Project Administration, J.A.A.; All authors have read and agreed to the published version of the manuscript.

Funding: This research received no external funding.

Acknowledgments: The support for the research presented in this paper was provided, in part, by Riad Sadek Endowed Chair in Civil Engineering and the Faculty Research Grants (FRG) Program of the American University of Sharjah. The support for publication and dissemination of the results of this study was provided by the Open Access Program (OAP) of the American University of Sharjah. The supports are gratefully appreciated and acknowledged. The views and conclusions, expressed or implied, in this study are those of the authors and should not be interpreted as those of the supporting institution.

Conflicts of Interest: The authors declared no conflict of interest.

\section{References}

1. Hollaway, L.C. A review of the present and future utilisation of FRP composites in the civil infrastructure with reference to their important in-service properties. Constr. Build. Mater. 2010, 24, 2419-2445. [CrossRef]

2. Pendhari, S.S.; Kant, T.; Desai, Y.M. Application of polymer composites in civil construction: A general review. Compos. Struct. 2008, 84, 114-124. [CrossRef]

3. Naser, M.; Hawileh, R.A.; Abdalla, J.A. Use of Fiber-Reinforced Polymer Composites in Strengthening Reinforced Concrete Structures: A Critical Review. J. Eng. Struct. 2019, 198, 109542. [CrossRef]

4. Siddika, A.; Al Mamun, M.A.; Alyousef, R.; Amran, Y.M. Strengthening of reinforced concrete beams by using fiber-reinforced polymer composites: A review. J. Build. Eng. 2019, 25, 100798. [CrossRef]

5. Cauich, P.J.P.; Martínez-Molina, R.; Marrufo, J.L.G.; Franco, P.J.H. Adhesion, strengthening and durability issues in the retrofitting of Reinforced Concrete (RC) beams using Carbon Fiber Reinforced Polymer (CFRP)-A Review. Rev. ALCONPAT 2019, 9, 130-151. [CrossRef]

6. Czaderski, C.; Meier, H. EBR Strengthening Technique for Concrete, Long-Term Behaviour and Historical Survey. Polymers 2018, 10, 77. [CrossRef]

7. Meier, U. Strengthening of structures using carbon fibre/epoxy composites. Constr. Build. Mater. 1995, 9, 341-351. [CrossRef]

8. Rahim, N.I.; Mohammed, B.S.; Al-Fakih, A.; Wahab, M.M.A.; Liew, M.S.; Anwar, A.; Amran, Y.H.M. Strengthening the Structural Behavior of Web Openings in RC Deep Beam Using CFRP. Materials 2020, 13, 2804. [CrossRef]

9. Chalioris, C.E.; Zapris, A.G.; Karayannis, C.G. U-Jacketing Applications of Fiber-Reinforced Polymers in Reinforced Concrete T-Beams against Shear-Tests and Design. Fibers 2020, 8, 13. [CrossRef]

10. Barros, J.A.O.; Dias, S.J.E.; Lima, J.L.T. Efficacy of CFRP-based techniques for the flexural and shear strengthening of concrete beams. Cem. Concr. Compos. 2007, 29, 203-217. [CrossRef] 
11. Alzoubi, F.; Zhengliang, L. Overview Shear Strengthening of RC Beams with Externally Bonded FRP Composites. J. Appl. Sci. 2007, 7, 1093-1106. [CrossRef]

12. Jumaat, M.Z.; Rahman, M.M.; Rahman, M.A. Review on bonding techniques of CFRP in strengthening concrete structures. Int. J. Phys. Sci. 2011, 6, 3567-3575. [CrossRef]

13. Mohammed, A.; Abdalla, J.A.; Hawileh, R.A.; Nawaz, W. Reinforced Concrete Beams Externally Strengthened in Flexure using Hybrid Systems. In Proceedings of the ASET 2018 First Multi Conference on Advances in Science and Engineering Technology-Advanced Materials, Design and Manufacturing International Conference, Dubai, UAE, 6-7 February 2018.

14. Önal, M.M. Strengthening Reinforced Concrete Beams with CFRP and GFRP. Adv. Mater. Sci. Eng. 2014, 8. [CrossRef]

15. Piątek, B.; Siwowski, T.; Michałowski, J.; Błażewicz, S. Development of Bonded/Riveted Steel Anchorages of Prestressed CFRP Strips for Concrete Strengthening. Materials 2020, 13, 2217. [CrossRef]

16. Jones, R.; Swamy, R.N.; Charif, A. Plate separation and anchorage of reinforced concrete beams strengthened by epoxy-bonded steel plates. Struct. Eng. 1988, 66, 85-94. Available online: http://worldcat.org/issn/14665123 (accessed on 12 January 2018).

17. Hawileh, R.A.; Nawaz, W.; Abdalla, J.A. Flexural behavior of reinforced concrete beams externally strengthened with Hardwire Steel-Fiber sheets. Constr. Build. Mater. 2018, 172, 562-573. [CrossRef]

18. Barnes, R.A.; Mays, G.C. Strengthening of reinforced concrete beams in shear by the use of externally bonded steel plates: Part 2-Design guidelines. Constr. Build. Mater. 2006, 20, 403-411. [CrossRef]

19. Aykac, S.; Kalkan, I.; Aykac, B.; Karahan, S.; Kayar, S. Strengthening and repair of reinforced concrete beams using external steel plates. J. Struct. Eng. 2013, 139, 929-939. [CrossRef]

20. Rakgate, S.M.; Dundu, M. Strength and ductility of simple supported R/C beams retrofitted with steel plates of different width-to-thickness ratios. Eng. Struct. 2018, 157, 192-202. [CrossRef]

21. Abdalla, J.A.; Hraib, F.H.; Hawileh, R.A.; Mirghani, A.M. Experimental investigation of bond-slip behavior of aluminum plates adhesively bonded to concrete. J. Adhes. Sci. Technol. 2017, 31, 82-99. [CrossRef]

22. Fayed, S.; Basha, A.; Hamoda, A. Shear strengthening of RC beams using aluminum plates: An experimental work. Constr. Build. Mater. 2019, 221, 122-138. [CrossRef]

23. Abdalla, J.A.; Abou-Obeidah, A.S.; Hawileh, R.A. Behavior of Shear Deficient Reinforced Concrete Beams with Externally Bonded Aluminum Alloy Plates. In Proceedings of the 2011 World Congress on Advances in Structural Engineering and Mechanics, Seoul, Korea, 18-23 September 2011.

24. Chang, H.; Zhou, W. Flexural Behaviour of Unbonded Posttensioned Concrete Beam Strengthened with Aluminium Alloy Plates. Math. Probl. Eng. 2020, 13. [CrossRef]

25. Abu-Obeidah, A.S.; Abdalla, J.A.; Hawileh, R.A. Shear strengthening of deficient concrete beams with marine grade aluminum alloy plates. Adv. Concr. Constr. 2019, 7, 249-262. [CrossRef]

26. Abdalla, J.A.; Abu-Obeidah, A.S.; Hawileh, R.A.; Rasheed, H.A. Shear strengthening of reinforced concrete beams using externally-bonded aluminum alloy plates: An experimental study. Constr. Build. Mater. 2016, 128, 24-37. [CrossRef]

27. Zhu, J.H.; Wei, L.L.; Zhu, M.C.; Li, W.W.; Xing, F. Experimental study of bond behavior on aluminum alloy plate-to-concrete interface. Appl. Mech. Mater. 2014, 501, 805-810. [CrossRef]

28. Abdalla, J.A.; Abu-Obeidah, A.S.; Hawileh, R.A. Use of Aluminum Alloy Plates as Externally Bonded Shear Reinforcement for R/C Beams. Procedia Struct. Integr. 2019, 17, 403-410. [CrossRef]

29. Rasheed, H.A.; Abdalla, J.A.; Hawileh, R.A.; Al-Tamimi, A.K. Flexural Behavior of Reinforced Concrete Beams Strengthened with Externally Bonded Aluminum Alloy Plates. Eng. Struct. 2017, 147, 473-485. [CrossRef]

30. Grelle, S.V.; Sneed, L.H. Review of Anchorage Systems for Externally Bonded FRP Laminates. Int. J. Concr. Struct. Mater. 2013, 7, 17-33. [CrossRef]

31. Kalfat, R.; Al-Mahaidi, R.; Smith, S. Anchorage Devices Used to Improve the Performance of Reinforced Concrete Beams Retrofitted with FRP Composites: State-of-the-Art Review. J. Compos. Constr. 2013, 17, 14-33. [CrossRef]

32. Mohee, F.M.; Al-Mayah, A.; Plumtree, A. Anchors for CFRP plates: State-of-the-art review and future potential. Compos. Part B Eng. 2016, 90, 432-442. [CrossRef]

33. Banijamali, S.M.; Esfahani, M.R.; Nosratollahi, S.; Sohrabi, M.R.; Mousavi, S.R. Reviewing the FRP strengthening systems. Am. J. Civ. Eng. 2015, 3, 38-43. [CrossRef] 
34. Ali, A.; Abdalla, J.A.; Hawileh, R.A.; Galal, K. CFRP Mechanical Anchorage for Externally Strengthened RC Beams under Flexure. Phys. Procedia 2014, 55, 10-16. [CrossRef]

35. Mhanna, H.H.; Hawileh, R.A.; Abdalla, J.A. Shear Strengthening of Reinforced Concrete Beams Using CFRP Wraps. Procedia Struct. Integr. 2019, 172019, 214-221. [CrossRef]

36. Mohamed, K.; Abdalla, J.A.; Hawileh, R.A.; Nawaz, W. Using bore-epoxy anchorage to delay debonding of CFRP plates strengthened concrete beams. In Proceedings of the ASET 2018 First Multi Conference on Advances in Science and Engineering Technology-Advanced Materials, Design and Manufacturing International Conference, Dubai, UAE, 6-7 February 2018; Available online: https://ieeexplore.iee.org/ abstract/document/8376863 (accessed on 20 August 2018).

37. Koutas, L.; Triantafillou, T.C. Use of anchors in shear strengthening of reinforced concrete T-beams with FRP. J. Compos. Constr. 2013, 17, 101-107. [CrossRef]

38. Kim, Y.; Quinn, K.; Ghannoum, W.M.; Jirsa, J.O. Strengthening of reinforced concrete T-beams using anchored CFRP materials. ACI Struct. J. 2014, 111, 1027. [CrossRef]

39. Chen, G.M.; Zhang, Z.; Li, Y.L.; Li, X.Q.; Zhou, C.Y. T-section RC beams shear-strengthened with anchored CFRP U-strips. Compos. Struct. 2016, 144, 57-79. [CrossRef]

40. Hawileh, R.A.; Nawaz, W.; Abdalla, J.A.; Saqan, E.I. Effect of Flexural CFRP Sheets on Shear Resistance of Reinforced Concrete Beams. Compos. Struct. 2015, 122, 468-476. [CrossRef]

41. Hawileh, R.; Nawaz, W.; Abdalla, J.; Saqan, E. External Strengthening of Shear Deficient Reinforced Concrete Beams with Flexural CFRP Laminates. In Response of Structures under Extreme Loading. Proceedings of the 5th International Workshop on Performance, Protection \& Strengthening of Structures under Extreme Loading (PROTECT 2015), East Lansing, MI, USA, 28-30 June 2015; DEStech Publications, Inc.: Lancaster, PA, USA, 2015; pp. 368-373. Available online: http://hdl.handle.net/11073/16369 (accessed on 8 July 2016).

42. Nawaz, W.; Hawileh, R.; Saqan, E.I.; Abdalla, J.A. Effect of Longitudinal CFRP Plates on the Shear Strength of RC Beams. ACI Struct. J. 2016, 113, 577-586. [CrossRef]

43. Saqan, E.; Nawaz, W.; Hawileh, R.; Abdalla, J. Evaluation of the contribution of flexural CFRP plates in shear strengthening RC beams. In Proceedings of the Third Conference on Smart Monitoring, Assesment and Rehabilitation of Civil Structures (SMAR 2015), Antalya, Turkey, 7-9 September 2015; p. 275. Available online: http://hdl.handle.net/11073/16235 (accessed on 10 June 2016).

44. Hosseini, A.; Mostofinejad, D. Experimental investigation into bond behavior of CFRP sheets attached to concrete using EBR and EBROG techniques. Compos. Part B Eng. 2013, 51, 130-139. [CrossRef]

45. Mostofinejad, D.; Kashani, A.T. Experimental study on effect of EBR and EBROG methods on debonding of FRP sheets used for shear strengthening of RC beams. Compos. Part B Eng. 2013, 45, 1704-1713. [CrossRef]

46. Mostofinejad, D.; Amirali, M.S.; Tabatabaei, K.A. Grooving Method to Postpone Debonding of FRP Sheets Used for Shear Strengthening. Proc. World Acad. Sci. Eng. Technol. 2012, 6, 795-799.

47. Moghaddas, A.; Mostofinejad, D. Empirical FRP-concrete bond strength model for externally bonded reinforcement on grooves. J. Compos. Constr. 2019, 23, 04018080. [CrossRef]

48. Riahi, A.T.; Moshiri, N.; Czaderski, C.; Mostofinejad, D. Effect of the EBROG method on strip-to-concrete bond behavior. Constr. Build. Mater. 2019, 220, 701-771. [CrossRef]

49. Moshiri, N.; Riahi, A.T.; Mostofinejad, D.; Czaderski, C.; Motavalli, M. Experimental and analytical study on CFRP strips-to-concrete bonded joints using EBROG method. Compos. Part B Eng. 2019, 158, 437-447. [CrossRef]

50. Czaderski, C.; Moshiri, N.; Hosseini, A.; Mostofinejad, D.; Motavalli, M. EBROG technique to enhance the bond performance of CFRP strips to concrete substrate. In Proceedings of the 5th International Conference on Smart Monitoring, Assessment and Rehabilitation of Civil Structures (SMAR 2019), Potsdam, Germany, 27-29 August 2019.

51. Mostofinejad, D.; Hosseini, S.A.; Razavi, S.B. Influence of different bonding and wrapping techniques on performance of beams strengthened in shear using CFRP reinforcement. Constr. Build. Mater. 2016, 116, 310-320. [CrossRef]

52. Mostofinejad, D.; Shameli, S.M. Externally bonded reinforcement in grooves (EBRIG) technique to postpone debonding of FRP sheets in strengthened concrete beams. Constr. Build. Mater. 2013, 38, 751-758. [CrossRef]

53. MAPEI Technical Worksheet. Available online: https://www.mapei.com/it/en/products-and-solutions/ products/detail (accessed on 15 June 2016). 
54. American Concrete Institute. ACI 440.2R-17. Guide for the Design and Construction of Externally Bonded FRP Systems for Strengthening Concrete Structures; American Concrete Institute: Farmington Hills, MI, USA, 2017.

55. Khalifa, A.; Gold, W.J.; Nanni, A.; Abdelaziz, M.I. Contribution of externally bonded FRP to shear capacity of RC flexural members. J. Compos. Constr. 1998, 2, 195-202. [CrossRef]

56. Bazant, Z.P.; Kim, J.K. Size effect in shear failure of longitudinally reinforced beams. ACI J. 1984, 81, 456-468.

57. Bazant, Z.P.; Kazemi, M.T. Size effect on diagonal shear failure of beams without stirrups. ACI Struct. J. 1991, 88, 268-276.

58. Zararis, P.D.; Papadakis, G.C. Diagonal shear failure and size effect in RC beams without web reinforcement. J. Struct. Eng. 2001, 127, 733-742. [CrossRef]

59. Bažant, Z.P.; Yu, Q. Designing against size effect on shear strength of reinforced concrete beams without stirrups: I. Formulation. J. Struct. Eng. 2005, 131, 1877-1885. [CrossRef]

60. Bentz, E.C. Empirical modeling of reinforced concrete shear strength size effect for members without stirrups. ACI Struct. J. 2005, 102, 232-241.

61. Matta, F.; El-Sayed, A.K.; Nanni, A.; Benmokrane, B. Size Effect on Concrete Shear Strength in Beams Reinforced with Fiber-Reinforced Polymer Bars. ACI Struct. J. 2013, 110, 617-628.

62. Alam, M.S.; Hussein, A. Size effect on shear strength of FRP reinforced concrete beams without stirrups. J. Compos. Constr. 2013, 17, 507-516. [CrossRef]

63. Syroka-Korol, E.; Tejchman, J. Experimental investigations of size effect in reinforced concrete beams failing by shear. Eng. Struct. 2014, 58, 63-78. [CrossRef]

(C) 2020 by the authors. Licensee MDPI, Basel, Switzerland. This article is an open access article distributed under the terms and conditions of the Creative Commons Attribution (CC BY) license (http://creativecommons.org/licenses/by/4.0/). 